\title{
Research Article \\ Sustainable Supplier Selection Based on Regret Theory and QUALIFLEX Method
}

\author{
Limei Liu ${ }^{1,2}$, Zhongli Bin ${ }^{1,2}$, Biao Shi ${ }^{1,2,}$, Wenzhi Cao ${ }^{1,2}$ \\ ${ }^{1}$ Base of International Science and Technology Innovation and Cooperation on Big Data Technology and Management, Hunan University of Technology and Business, \\ 569, YueLu Avenue, Changsha, 410205, Hunan, P.R. China \\ ${ }^{2}$ Key Laboratory of Hunan Province for New Retail Virtual Reality Technology, Hunan University of Technology and Business, 569, YueLu Avenue, Changsha, 410205, \\ Hunan, P.R. China
}

\section{ARTICLE INFO}

Article History

Received 28 Dec 2019

Accepted 27 Jul 2020

\section{Keywords}

Sustainable supplier selection Bounded rantionality

2-dimension at uncertain linguistic variable

Regret theory

QUALIFLEX

\begin{abstract}
Sustainable supplier selection is the essential core of sustainable supply chain management, which can directly influence the manufacturer's performance and can enormously enhance the manufacturer's competitiveness in the international market. However, most of the previous studies concerning sustainable supplier selection have less focused on the reliability of the decision-makers judgments and the application of regret theory. To fill this gap, we presented an integrated sustainable supplier selection model based on regret theory and QUALItative FLEXible multiple criteria method (QUALIFLEX) under a 2-dimensional uncertain linguistic variable (2-DULV) environment. In the proposed model, 2-DULV including the reliability of evaluation information is employed to handle the uncertainty and vagueness of decision-makers judgments. A similarity-based method is used to derive the decision-makers' weight, and a maximizing deviation model is established to calculate the weights of evaluation criteria. Then an improved QUALIFLEX method based on regret theory is presented to obtain the ranking order of sustainable suppliers. The proposed approach integrates both the superiority of 2-DULV in effectively handling the uncertainty, vagueness, and reliability of evaluation information and the merit of regret theory in dealing with decision-maker's bounded rationality. Finally, a numerical example concerning an automobile manufacturer is provided to validate the effectiveness and feasibility of the presented model.
\end{abstract}

(C) 2020 The Authors. Published by Atlantis Press B.V. This is an open access article distributed under the CC BY-NC 4.0 license (http://creativecommons.org/licenses/by-nc/4.0/).

\section{INTRODUCTION}

In modern society, governments, businesses, and individuals increasingly focus on social responsibility and environmental protection. Sustainable supply chain management (SSCM) can not only reduce environmental pollution in supply chain activities but also enhance the competitive superiority of enterprises, so SSCM is recognized as a new management model, and has attracted more and more attention from researchers and practitioners [1-5]. In the SSCM activities, sustainable supplier selection can be thought of as a conventional supplier selection taking into account the economic, environmental, and social dimensions [6,7]. Sustainable supplier selection plays an important role in the SSCM [8], which both enhances the satisfaction degree and product quality and directly influences the enterprise's environmental performance and competitive advantages. Therefore, how to choose the most suitable sustainable supplier, which is the main focus of this study, has a greatly critical role for enterprises success.

Generally speaking, sustainable supplier selection involves multiple criteria and alternatives, so it's usually called a multi-criteria decision-making (MCDM) problem, including the evaluation and

\footnotetext{
*Corresponding author. Email: 2698@hnuc.edu.cn
}

ranking of sustainable suppliers. In the assessment of sustainable suppliers, it's very difficult for decision-makers to represent the evaluation information by a precise number, owing to the complexity of the assessment object and the vagueness and uncertainty of human judgments $[9,10]$. To handle this problem, many of fuzzy set theories have been used to deal with ambiguity and uncertainty of decision-makers' evaluation, such as interval-valued fuzzy set $[11,12]$, intuitionistic fuzzy set $[4,13,14]$, and uncertain linguistic variable [15]. Although these approaches can effectively deal with vagueness and uncertainty information, it has not addressed the reliability of evaluation information.

In practice, decision-makers not only provide the assessment information on the evaluation object but also express the reliability of their assessment information [16]. To cope with this issue, Liu [16] presented the 2-dimensional uncertain linguistic variable (2-DUVL) concept, including the evaluation information and its reliability, to characterize the ambiguity and uncertainty of decision-makers' assessment information. 2-DULV has been used for various fields under uncertain environment owing to its apparent advantage. For instance, failure mode and effect analysis [17], site selection of power plant [18], and emergency management [19]. Therefore, 2-DULV is utilized to represent the evaluation information of decision-makers in this paper. 
After obtaining the evaluation information, several MCDM methods, such as techniques for order preferences by similarity to ideal solution (TOPSIS) [20], preference ranking organization method for enrichment evaluation (PROMETHEE) [21], and weighted aggregated sum product assessment (WASPAS) [22] approaches, were generally used to derive the ranking of sustainable suppliers. Compared with other MCDM approaches, the obvious advantages of the QUALIFLEX approach can be summarized as [23]: (1) Its calculation process is very simple and easy to be operated and implemented; (2) It can effectively deal with cardinal and ordinal information under different criteria in the MCDM problem; and (3) It is especially suitable to handle MCDM problems involving a number of criteria and fewer alternatives. Due to the above merits, Wang et al. [23] developed an integrated MCDM model combining the cloud model and QUALIFLEX method to evaluate the green performance of companies, and Liang and Chong [24] established a hybrid group decision model based on the QUALIFLEX approach to handle the green supplier selection under a complex situation. However, most of the previous studies generally assume that decision-makers are completely rational.

In practical decision activities, decision-maker's behavior is bounded rationality due to their cognition and knowledge limitation, time pressure as well as incomplete information [25]. In this situation, a decision deviation is usually generated between the practical and expected decision results. To handle this situation, prospect theory [26], cumulative prospect theory [27], and TODIM approaches [5] have been used to deal with the sustainable supplier selection problem. Regret theory presented by Loomes and Sugden [28] and Bell [29] is also a bounded rationality theory. It has been extensively applied in different fields, such as risk assessment [30], electronic commerce [31], and development program selection [32] because it well explains and predicts decision-makers' psychological behavior and is simpler than the prospect theory. In addition, according to the advantages of the QUALIFLEX method, QUALIFLEX is suitable to derive the ranking of sustainable suppliers including multiple criteria and limited alternatives. A small number of previous researchers have explored the issue of sustainable supplier selection under bounded rationality context, but there is no study combining regret theory and QUALIFLEX method, especially under the 2-DULV environment. Consequently, it is necessary to propose a hybrid model integrating regret theory and QUALIFLEX approach to fill gaps in existing researches.

To further handle the sustainable supplier selection problem with considering the reliability of evaluation information and decisionmakers' psychological behavior, we present a hybrid MCDM model by integrating the regret theory and QUALIFLEX method for evaluating and selecting sustainable suppliers within the 2-DULV environment. Besides, the weights of decision-makers and the weights of evaluation criteria are calculated by an objective weight method. The main contribution of this study to literature can be summarized as follows:

i. To effectively handle the uncertainty and vagueness of the decision-makers judgments and depict the assessment reliability of decision-makers simultaneously, 2-DULV is utilized to represent the evaluation information of decision-makers.

ii. Decision-makers should be assigned a reasonable weight because of their different experience and knowledge background. In much previous literature, the weights of decision-makers are subjectively given according to their experience. To assign weight reasonably, the weights of decision-makers in this study are obtained by similarity-based methods.

iii. Decision-makers are generally bounded rationality due to the limitations of their cognition and knowledge. To depict this feature, in this paper, an improved QUALIFLEX method based on regret theory (QUALIFLEX-RT) is presented to derive the ranking of sustainable suppliers.

The remainder of this paper is arranged as follows: Related research is provided in Section 2. In Section 3, we propose a hybrid MCDM method utilizing 2-DULVs, regret theory, and QUALIFLEX approach for sustainable supplier selection. A numerical example concerning an automobile manufacturer is provided to implement the proposed approach in Section 4. Finally, Section 5 provides the conclusions of this paper and points out the direction of future studies.

\section{RELATED WORKS}

In this section, we should introduce the related works, including the methods of sustainable supplier selection, 2-dimensional uncertainty linguistic variable, QUALIFLEX method, and regret theory.

\subsection{Methods of Sustainable Supplier Selection}

To enhance the competitive advantages, many approaches were employed by enterprises to derive the prioritization of sustainable suppliers in the past decade. According to whether considering the decision-makers' psychological behavior, these methods can be divided into two categories, namely, approaches of complete rationality and methods of bounded rationality. For the former approaches, for example, $\mathrm{Li}$ et al. [20] proposed an extended TOPSIS approach to choose a sustainable supplier, using cloud model theory and rough set theory to handle intrapersonal uncertainty and interpersonal uncertainty, respectively. Through combining the revised Simos procedure, PROMETHEE approach, compromise ranking, and robustness analysis, Govindan et al. [21] presented a hybrid model to choose the best green supplier in the food supply chain. Mishra et al. [22] utilized a hesitant fuzzy set to deal with the uncertainty in the green supplier selection and developed an integrated approach based on the WASPAS method. Lu et al. [33] explored the sustainable supplier selection of solar air-conditioner manufacturers by integrating rough set theory and ELECTRE approach. To handle green supplier selection, Wu et al. [34] established a hybrid model based on the best-worst method and vise kriterijumska optimizacija i kompromisno resenje (VIKOR) method. For the latter methods, for instance, Phochanickorn and Tan [26] presented an integrated MCDM model combing fuzzy decision-making trial and evaluation laboratory, fuzzy analytic network process, and prospect theory, for green supplier selection. Liao et al. [27] applied the knowledge of thermodynamics, cumulative prospect theory, and PROMETHEE II method to design an integrating approach for green logistic provider selection. 
To choose the best green supplier within the environment of interval type-2 fuzzy sets, Qin et al. [5] proposed an extended TODIM approach, which can depict the bounded rationality behavior of decision-makers.

\subsection{2-dimensional Uncertainty Linguistic Variable}

The 2-DULV, including the evaluation information and its reliability, was put forward by Liu [16] to characterize the ambiguity and uncertainty of decision-makers' assessment information. 2-DULV adopts I class uncertain linguistic variable $S_{I}$ and II class uncertain linguistic variable $S_{I I}$ to denote the assessment grade and the reliability evaluated by decision-makers, respectively [16]. 2-DULV has been used for various fields under uncertain environment owing to its apparent advantages. For instance, Liu et al. [17] improved failure mode and effect analysis, employing 2-DULV to express the evaluation of decision-makers and using alternative queuing method to derive the ranking of failure modes. Wu et al. [18] studied a site selection of straw biomass power plant by building a specialized decision framework, combining the 2-DULV and cloud model theory. To identify the critical success factors in emergency management, Ding and Liu [19] introduced a new approach based on 2-DULV and decision-making trial and evaluation laboratory. Liu et al. [35] proposed a series of 2-DULV operators based on the improved operational laws of 2-DULV, and applied them to deal with MCDM problems.

\subsection{QUALIFLEX Method}

QUALIFLEX approach was initially proposed by Paelinck [36], which is a useful outranking approach in MCDM. QUALIFLEX method is very suitable for solving MCDM problems involving a number of criteria and fewer alternatives [23], so it has been widely employed to deal with various MCDM problems in practice. For example, Chen et al. [37] introduced an extended QUALIFLEX method for dealing with the medical decision-making problem under the interval type-2 fuzzy sets environment. Dong et al. [38] developed a novel QUALIFLEX method based on a cosine similarity to evaluate financial performance. To solve an MCDM issue considering the decision-makers' psychological behavior, Tian et al. [39] presented a decision model by combining the regret theory and QUALIFLEX method to assess the risk of high-tech project investment. Wang et al. [40] proposed a hybrid MCDM approach to handle building energy efficiency retrofitting project selection problem, adopting a picture fuzzy TOPSIS-based QUALIFLEX approach to determine the ranking order of alternatives.

\subsection{Regret Theory}

Loomes and Sugden [28] and Bell [29] separately proposed the regret theory to characterize the psychological behavior of decisionmakers under uncertainty environment. In decision-making, they deem that decision-makers not only take the outcomes of the selected alternative into account but also focus on the results of the chose alternative relative to other alternatives. Regret theory has been extensively applied in different fields, such as risk assessment [30], electronic commerce [31], and development program selection [32] because it well explains and predicts decision-makers' psychological behavior and is simpler than prospect theory.

In regret theory, expected utility function proposed by Von Neumann and Morgenstern [41] is expanded to the perceived utility function, which is consist of the utility function of current selection results and regret-rejoicing function. Assume that $a$ and $b$ express the outcomes of choosing alternative $A$ and $B$, respectively. Then the obtained perceived utility from choosing $A$ is represented as

$$
U(a, b)=v(a)+R(v(a)-v(b)) .
$$

where $v(\cdot)$ represents the utility function satisfying $v^{\prime}(\cdot)>0$ and $v^{\prime \prime}(\cdot)<0 . v(a)$ and $v(b)$ are the utility value that came from choosing alternative $A$ and $B$, respectively. Power function $\left(v(x)=x^{\alpha}\right)$ is usually utilized to calculate the utility value of alternative concerning criteria, where $\alpha(0<\alpha<1)$ denotes the risk aversion coefficient of decision-makers [42]. A smaller $\alpha$ implies a greater risk aversion degree. $R(\cdot)$ expresses the regret-rejoicing function that is a strictly and monotonically increasing concave function, such that $R^{\prime}(\cdot)>0, R^{\prime \prime}(\cdot)<0$ and $R(0)=0$. Bell [29] and Chorus [43] adopt the function $(R(\Delta v)=1-\exp (-\delta \Delta v))$ to represent the regretregret function, where $\delta$ stands for the regret aversion degree of decision-maker. A larger $\delta$ implies a greater regret aversion degree. $R(v(a)-v(b))$ is the regret-rejoicing utility value obtained from choosing alternative $A$ comparied to $B$. It stands for the regret and rejoicing when $R(v(a)-v(b))<0$ and $R(v(a)-v(b))>0$, separately.

Regret theory was initially used to choose of pairwise alternative. In practice, decision-makers usually face multiple alternatives when they choose the optimal alternative. To deal with this situation, regret theory was extended to general choice sets by Quiggin [44]. Regret theory involving multiple alternatives can be depicted as follows. Let $A=\left\{A_{1}, A_{2}, \cdots, A_{m}\right\}$ be the set of $m$ alternatives and $x_{i}$ be the results of choosing alternative $A_{i}(i=1,2, \cdots, m)$, then decision-maker's perceived utility of choosing $A_{i}$ is defined as

$$
U\left(A_{i}\right)=v\left(x_{i}\right)+R\left(v\left(x_{i}\right)-v\left(x^{*}\right)\right) .
$$

where $x^{*}=\max \left\{x_{i} \mid i=1,2, \cdots, m\right\}$, and $R\left(v\left(x_{i}\right)-v\left(x^{*}\right)\right)$ represents the regret value when decision-maker choosing alternative $A_{i}$ rather than $x^{*}$

To our knowledge, existing literature rarely uses the regret theory to handle the problem of sustainable supplier selection considering the bounded rationality of decision-makers, especially in the 2-DULV context. Aiming at filling this research gap, this paper proposes a novel approach combing regret theory and QUALIFLEX method under the 2-DULV environment.

\section{PRESENTED MODEL}

In this section, we will present an improved QUALIFLEX-RT for sustainable suppliers selection considering the regret aversion behavior of decision-makers under the 2-DULV environment. The flowchart of the presented model is shown in Figure 1.

To convenient for description of the proposed approach, the relevant variables applied in this study are provided as follows:

- $S=\left\{S_{1}, S_{2}, \ldots, S_{i}, \ldots, S_{m}\right\}$ expresses a set of $m$ alternative sustainable suppliers. 


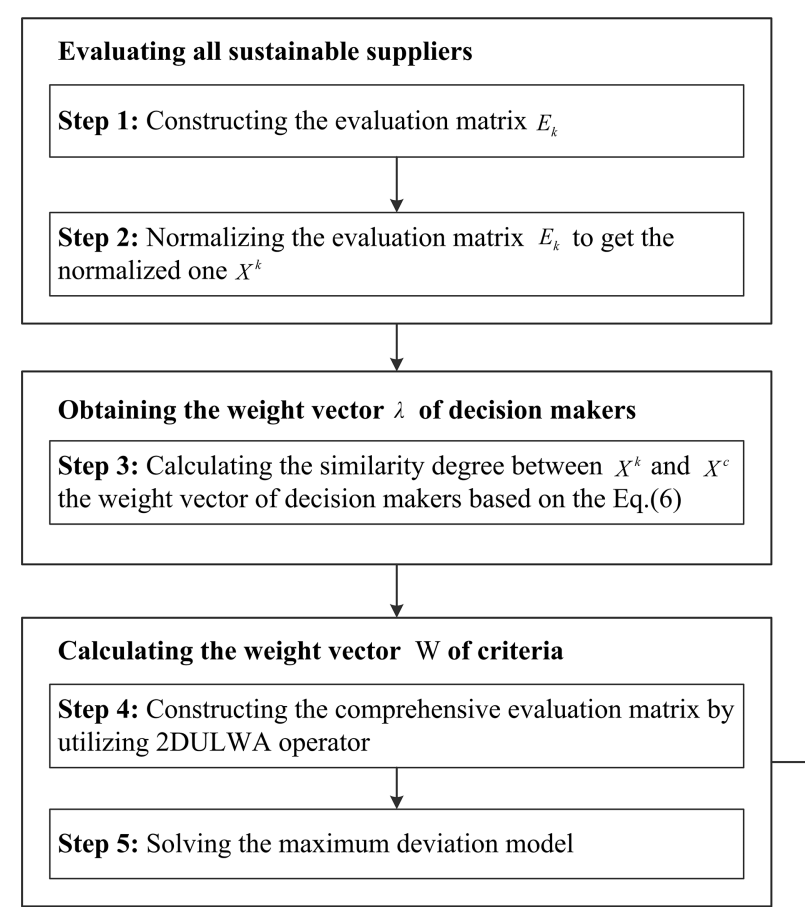

Figure $1 \mid$ Flowchart of the presented model.

- $C=\left\{C_{1}, C_{2}, \ldots, C_{j}, \ldots, C_{n}\right\}$ expresses a set of $n$ evaluation criteria.

- $D=\left\{D_{1}, D_{2}, \ldots, D_{k}, \ldots, D_{q}\right\}$ expresses a set of $q$ decision-makers.

- $\lambda=\left(\lambda_{1}, \lambda_{2}, \ldots, \lambda_{q}\right), \lambda_{k} \geqslant 0, \sum_{k=1}^{q} \lambda_{k}=1$ denotes the weight of decision-makers.

- $W=\left(w_{1}, w_{2}, \ldots, w_{n}\right), w_{j} \geqslant 0, \sum_{j=1}^{n} w_{j}=1$ denotes the weight of evaluation criteria.

- $S_{I}=\left\{\dot{s}_{0}, \dot{s}_{1}, \ldots, \dot{s}_{l-1}\right\}$ is a predefined linguistic term set.

- $S_{I I}=\left\{\ddot{s}_{0}, \ddot{s}_{1}, \ldots, \ddot{s}_{t-1}\right\}$ is a predefined linguistic term set.

- $I_{B}$ and $I_{C}$ indicates the benefit criteria and cost criteria, respectively.

- $E_{k}=\left(e_{i j}^{k}\right)_{m \times n}$ indicates the 2-DULV evaluation matrix provided by $D_{k}$.

- $X^{k}=\left(x_{i j}^{k}\right)_{m \times n}$ indicates the normalized 2-DULV evaluation matrix of $D_{k}$.

- $X=\left(x_{i j}\right)_{m \times n}$ indicates the comprehensive 2-DULV evaluation matrix.

- $X^{c}=\left(x_{i j}^{c}\right)_{m \times n}$ indicates the ideal group evaluation matrix.

Based on the above variables, the presented QUALIFLEX-RT method for sustainable suppliers selection can be depicted as follows.

\subsection{Derive the Weights of Decision-Makers}

The similarity-based method is an objective weight method, which can fully utilize the evaluation information provided by

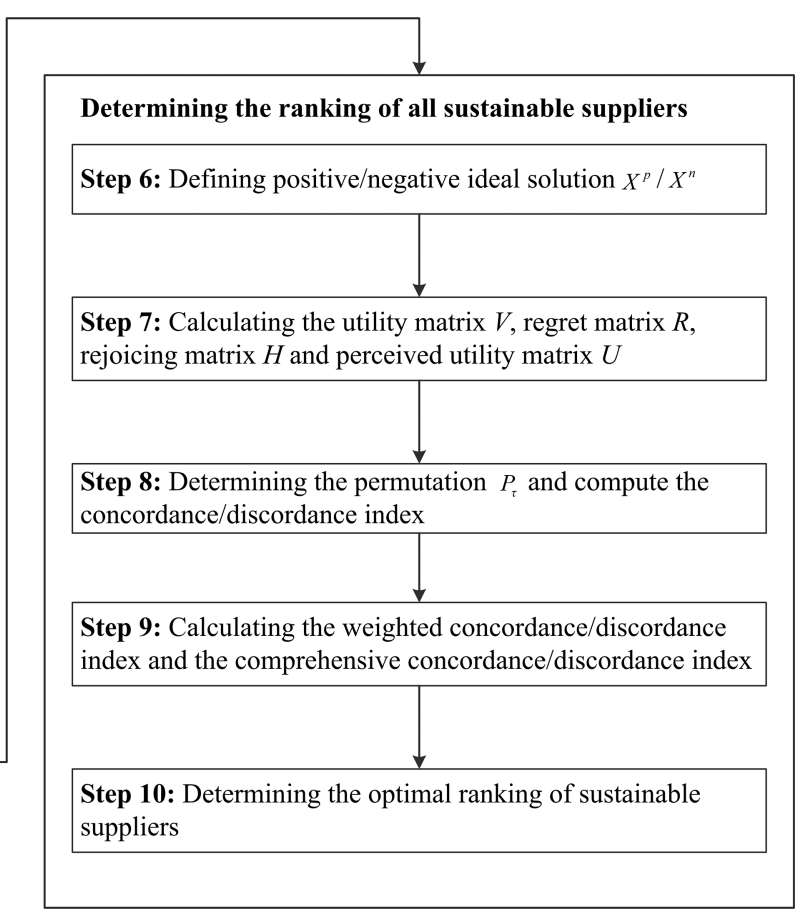

decision-makers to derive their weight. Its primary thinking is that the larger the similarity between the decision-maker's evaluation matrix and ideal group evaluation matrix, the greater weight should be assigned to the decision-maker, contrariwise, a smaller weight is assigned. Therefore, to calculate the weights of decision-makers according to a similarity-based method, we firstly define the similarity degree between any two 2-DULVs.

Definition 1. Let $s_{1}=\left(\left[\dot{s}_{a_{1}}, \dot{s}_{b_{1}}\right],\left[\ddot{s}_{c_{1}}, \ddot{s}_{d_{1}}\right]\right)$ and $s_{2}=$ $\left(\left[\dot{s}_{a_{2}}, \dot{s}_{b_{2}}\right],\left[\ddot{s}_{c_{2}}, \ddot{s}_{d_{2}}\right]\right)$ be any two 2-DULVs, the similarity degree between $s_{1}$ and $s_{2}$ is defined as

$$
\operatorname{sim}\left(s_{1}, s_{2}\right)=1-d\left(s_{1}, s_{2}\right)
$$

where $d\left(s_{1}, s_{2}\right)$ is the Hamming distance defined by Liu and Yu [45]. Apparently, $\operatorname{sim}\left(s_{1}, s_{2}\right)$ satisfies the following properties: (1) $0 \leqslant \operatorname{sim}\left(s_{1}, s_{2}\right) \leqslant 1 ;(2) \operatorname{sim}\left(s_{1}, s_{2}\right)=1$, if $s_{1}=s_{2} ;$ (3) $\operatorname{sim}\left(s_{1}, s_{2}\right)=$ $\operatorname{sim}\left(s_{2}, s_{1}\right)$.

The ideal group decision matrix can be constructed by 2-dimensional uncertain linguistic weighted averaging operator (2-DULWA) [35].

$$
X^{c}=\left(x_{i j}^{c}\right)_{m \times n}=\left(\begin{array}{cccc}
x_{11}^{c} & x_{12}^{c} & \ldots & x_{1 n}^{c} \\
x_{21}^{c} & x_{22}^{c} & \ldots & x_{2 n}^{c} \\
\vdots & \vdots & \ddots & \vdots \\
x_{m 1}^{c} & x_{m 2}^{c} & \ldots & x_{m n}^{c}
\end{array}\right)
$$

where $x_{i j}^{c}=\left(\left[\dot{s}_{a_{i j}^{c}}, \dot{s}_{b_{i j}^{c}}\right],\left[\ddot{s}_{c_{i j}^{c}}, \ddot{s}_{d_{i j}^{c}}\right]\right)=\frac{1}{q} \sum_{k=1}^{q} x_{i j}^{k}$. According to 2-DULWA operator, $a_{i j}^{c}=\sum_{k=1}^{q}\left(\frac{1}{q} a_{i j}^{k}\right), b_{i j}^{c}=\sum_{k=1}^{q}\left(\frac{1}{q} a_{i j}^{k}\right)$, 
$c_{i j}^{c}=(t-1)\left(1-\prod_{k=1}^{q}\left(1-\frac{c_{i j}^{c}}{t-1}\right)^{\frac{1}{q}}\right)$ and $d_{i j}^{c}=(t-$ 1) $\left(1-\prod_{k=1}^{q}\left(1-\frac{d_{i j}^{c}}{t-1}\right)^{\frac{1}{q}}\right)$.

If the evaluation matrix $X^{k}$ of decision-makers $D_{k}$ is closer to the ideal group evaluation matrix $X^{c}$, the better the $k$ th decisionmaker's evaluation matrix $X^{k}$. Then $D_{k}$ should be assigned a greater weight compared with other decision-makers. The $k$ th decisionmaker's weight can be calculated by

$$
\lambda_{k}=\frac{\operatorname{sim}\left(X^{k}, X^{c}\right)}{\sum_{k=1}^{q} \operatorname{sim}\left(X^{k}, X^{c}\right)}
$$

where $\operatorname{sim}\left(X^{k}, X^{c}\right)$ is the similarity degree between $X^{k}$ and $X^{c}$, namely, $\operatorname{sim}\left(X^{k}, X^{c}\right)=\sum_{i=1}^{m} \sum_{j=1}^{n} \operatorname{sim}\left(x_{i j}^{k}, x_{i j}^{c}\right)$.

After that, the comprehensive evaluation matrix $X=\left(x_{i j}\right)$ is obtained by combining the weights of decision-makers and 2DULWA operator, where $x_{i j}$ is computed by

$$
\begin{aligned}
x_{i j} & =2-\operatorname{DULWA}\left(x_{i j}^{1}, x_{i j}^{2}, \ldots, x_{i j}^{q}\right) . \\
& =\left(\left[\dot{s}_{a}, \dot{s}_{b}\right],\left[\ddot{s}_{c}, \ddot{s}_{d}\right]\right)
\end{aligned}
$$

where $a=\sum_{k=1}^{q}\left(\lambda_{k} a_{i j}^{k}\right), b=\sum_{k=1}^{q}\left(\lambda_{k} b_{i j}^{k}\right), c=(t-1)(1-$ $\left.\prod_{k=1}^{q}\left(1-\frac{c_{i j}^{k}}{t-1}\right)^{\lambda_{k}}\right)$ and $d=(t-1)\left(1-\prod_{k=1}^{q}\left(1-\frac{d_{i j}^{k}}{t-1}\right)^{\lambda_{k}}\right)$.

\subsection{Calculate the Weights of Criteria}

Generally speaking, if the values $x_{i j}$ of all alternatives under the criterion $C_{j}$ have a significant difference, this indicates that the criterion $C_{j}$ has a greater contribution in the ranking of alternatives, so the criterion $C_{j}$ should be given greater weight. In contrast, the smaller the deviation among the values $x_{i j}$ of all alternatives under the criterion $C_{j}$ is, the less important for criterion $C_{j}$ is, so we can assign less weight to this criterion. Therefore, the maximizing deviation method [46] is employed to derive the criteria weight.

According to the thinking of maximizing deviation method, the maximizing deviation model can be constructed as follows:

$$
\begin{array}{r}
\max D\left(w_{j}\right)=\sum_{j=1}^{n} \sum_{i=1}^{m} \sum_{l=1}^{m} d\left(x_{i j}, x_{l j}\right) w_{j} . \\
\left\{\begin{array}{l}
\text { s.t. } \sum_{j=1}^{n} w_{j}^{2}=1 \\
w_{j} \geqslant 0,(j=1,2, \ldots, n)
\end{array}\right.
\end{array}
$$

where $D\left(w_{j}\right)$ denotes the total sum of deviation for all suppliers with regard to all criteria and $d\left(x_{i j}, x_{l j}\right)$ represents the distance between $x_{i j}$ and $x_{l j}$.
To solve the equation above, Lagrange multiplier function is constructed as follows:

$$
L\left(w_{j}, \sigma\right)=\sum_{j=1}^{n} \sum_{i=1}^{m} \sum_{l=1}^{m} d\left(x_{i j}, x_{l j}\right) w_{j}+\frac{1}{2} \sigma\left(\sum_{j=1}^{n} w_{j}^{2}-1\right) .
$$

Let the first-order partial derivative of Eq. (7) be 0 ,

$$
\left\{\begin{array}{l}
\frac{\partial L\left(w_{j}, \sigma\right)}{\partial w_{j}}=\sum_{i=1}^{m} \sum_{l=1}^{m} d\left(x_{i j}, x_{l j}\right)+\sigma w_{j}=0 \\
\frac{\partial L\left(w_{j}, \sigma\right)}{\partial \sigma}=\sum_{j=1}^{n} w_{j}^{2}-1=0
\end{array} .\right.
$$

Then we have

$$
\left\{\begin{array}{l}
\sigma=\sqrt{\sum_{j=1}^{n}\left(\sum_{i=1}^{m} \sum_{l=1}^{m} d\left(x_{i j}, x_{l j}\right)\right)^{2}} \\
w_{j}=\frac{\sum_{i=1}^{m} \sum_{l=1}^{m} d\left(x_{i j}, x_{l j}\right)}{\sqrt{\sum_{j=1}^{n}\left(\sum_{i=1}^{m} \sum_{l=1}^{m} d\left(x_{i j}, x_{l j}\right)\right)^{2}}} .
\end{array}\right.
$$

Normalize the criteria weight, we have

$$
w_{j}=\frac{\sum_{i=1}^{m} \sum_{l=1}^{m} d\left(x_{i j}, x_{l j}\right)}{\sum_{j=1}^{n} \sum_{i=1}^{m} \sum_{l=1}^{m} d\left(x_{i j}, x_{l j}\right)} .
$$

\subsection{Rank the Sustainable Suppliers by QUALIFLEX Method Based on Regret Theory}

According to the evaluation matrix and the weights of decisionmakers and criteria, we presented an improved QUALIFLEX approach based on regret theory to determine the ranking of sustainable suppliers.

Define the positive ideal solution (PIS) $\left(X^{P}\right)$ and the negative ideal solution (NIS) $\left(X^{n}\right)$ on criteria.

$$
\begin{aligned}
& X^{p}=\left(x_{1}^{p}, x_{2}^{p}, \ldots, x_{n}^{p}\right)=\left(\left[\dot{s}_{a_{j}^{p}}, \dot{s}_{b_{j}^{p}}\right],\left[\ddot{s}_{c_{j}^{p}}, \ddot{s}_{d_{j}^{p}}\right]\right) . \\
& X^{n}=\left(x_{1}^{n}, x_{2}^{n}, \ldots, x_{n}^{n}\right)=\left(\left[\dot{s}_{a_{j}^{n}}, \dot{s}_{b_{j}^{n}}\right],\left[\ddot{s}_{c_{j}^{n}}, \ddot{s}_{d_{j}^{n}}\right]\right) .
\end{aligned}
$$

where $a_{j}^{p}=\max _{i}\left(a_{i j}^{p}\right), b_{j}^{p}=\max _{i}\left(b_{i j}^{p}\right), c_{j}^{p}=\max _{i}\left(c_{i j}^{p}\right), d_{j}^{p}=\max _{i}\left(d_{i j}^{p}\right)$, $a_{j}^{n}=\min _{i}\left(a_{i j}^{p}\right), b_{j}^{n}=\min _{i}\left(b_{i j}^{p}\right), c_{j}^{n}=\min _{i}\left(c_{i j}^{p}\right)$ and $d_{j}^{n}=\min _{i}\left(d_{i j}^{p}\right)$.

Then, depending on the utility function, the utility matrix of sustainable suppliers is calculated by

$$
V=\left(v_{i j}\right)=\left(\begin{array}{cccc}
v_{11} & v_{12} & \ldots & v_{1 n} \\
v_{21} & v_{22} & \ldots & v_{2 n} \\
\vdots & \vdots & \ddots & \vdots \\
v_{m 1} & v_{m 2} & \ldots & v_{m n}
\end{array}\right)
$$

where $v_{i j}=\left(E\left(x_{i j}\right)\right)^{\alpha}$. 
According to the regret-rejoicing function, the regret and rejoicing matrices of sustainable suppliers can be constructed as follows:

$$
\begin{gathered}
R=\left(r_{i j}\right)=\left(\begin{array}{cccc}
r_{11} & r_{12} & \ldots & r_{1 n} \\
r_{21} & r_{22} & \ldots & r_{2 n} \\
\vdots & \vdots & \ddots & \vdots \\
r_{m 1} & r_{m 2} & \ldots & r_{m n}
\end{array}\right) . \\
H=\left(h_{i j}\right)=\left(\begin{array}{cccc}
h_{11} & h_{12} & \ldots & h_{1 n} \\
h_{21} & h_{22} & \ldots & h_{2 n} \\
\vdots & \vdots & \ddots & \vdots \\
h_{m 1} & h_{m 2} & \ldots & h_{m n}
\end{array}\right) .
\end{gathered}
$$

where $r_{i j}=1-\exp \left(-\delta\left(v_{i j}-v\left(E\left(x_{j}^{p}\right)\right)\right)\right.$ and $h_{i j}=1-\exp \left(-\delta\left(v_{i j}-\right.\right.$ $\left.v\left(E\left(x_{j}^{n}\right)\right)\right)$.

After that, the perceived utility matrix $U=\left(u_{i j}\right)$ of sustainable supplier is obtained by

$$
U=\left(u_{i j}\right)=\left(\begin{array}{cccc}
u_{11} & u_{12} & \ldots & u_{1 n} \\
u_{21} & u_{22} & \ldots & u_{2 n} \\
\vdots & \vdots & \ddots & \vdots \\
u_{m 1} & u_{m 2} & \ldots & u_{m n}
\end{array}\right) .
$$

where $u_{i j}=v_{i j}+r_{i j}+h_{i j}$.

For the $m$ sustainable suppliers $S_{i}(i=1,2, \ldots, m)$, there exists $m$ ! permutation for the ranking of sustainable suppliers. Assume that the $\tau$ th permutation denoted by $P_{\tau}$ is expressed as

$$
P_{\tau}=\left(\ldots, S_{\rho}, \ldots, S_{\eta}\right), \tau=1,2, \ldots, m ! .
$$

where $S_{\rho}$ and $S_{\eta},(\rho, \eta=1,2, \cdots, \mathrm{m})$, are the alternative sustainable suppliers, and the priority level of $S_{\rho}$ is larger than or equal to $S_{\eta}$.

In the $\tau$ th permutation under the criterion $C_{j}$, the concordance/discordance index (CDI) $\phi_{j}^{\tau}\left(S_{\rho}, S_{\eta}\right)$ of each pair of sustainable suppliers $S_{\rho}$ and $S_{\eta}$ is defined as

$$
\phi_{j}^{\tau}\left(S_{\rho}, S_{\eta}\right)=u_{\rho j}-u_{\eta j}, j=1,2, \ldots, n .
$$

Considering the weight vector $W$ of criteria, the weighted CDI $\phi^{\tau}\left(S_{\rho}, S_{\eta}\right)$ of permutation $P_{\tau}$ for each pair of sustainable suppliers $\left(S_{\rho}, S_{\eta}\right)$ with regard to all criteria can be calculated by

$$
\phi^{\tau}\left(S_{\rho}, S_{\eta}\right)=\sum_{j=1}^{n} \phi_{j}^{\tau}\left(S_{\rho}, S_{\eta}\right) w_{j} .
$$

For the permutation $P_{\tau}$, the comprehensive CDI $\phi^{\tau}$ can be computed by

$$
\phi^{\tau}=\sum_{S_{\rho}, S_{\eta} \in S j=1} \sum_{j}^{n} \phi_{j}^{\tau}\left(S_{\rho}, S_{\eta}\right) w_{j} .
$$

According to the Eq. (20), we can know that the higher the comprehensive CDI value $\phi^{\tau}$, the better the corresponding permutation $P_{\tau}$. Consequently, the permutation $P_{\tau}$ with the greatest comprehensive CDI value $p h i^{\tau}$ is the optimal ranking order of all sustainable suppliers.

Based on the analysis above, the selection flow of sustainable supplier under 2-DULV environment can be summarized as follows:
Step 1: Obtain the evaluation information of supplier $S_{i}$ provided by decision-maker $D_{k}$ with 2-DULV on criterion $C_{j}$, and construct evaluation matrix $E_{k}=\left(e_{i j}^{k}\right)_{m \times n}$.

Step 2: Normalize the evaluation matrix $E_{k}$ to get the normalized one $X^{k}$

For the criterion $C_{j} \in I_{B}$, the evaluation information does not require change. For the criterion $C_{j} \in I_{C}$, the I class uncertain linguistic information is normalized by taking the opposite value of the original value. For instance, let $S_{I}=\left(s_{0}, s_{1}, \ldots, s_{l}\right)$ be a linguistic term set, given the I class uncertain linguistic information $\left[s_{a}, s_{b}\right]$, then the normalized value is $\left[s_{l-b}, s_{l-a}\right]$.

Step 3: Determine the weight vector $\lambda$ of decision-makers based on the Eqs. (3) and (4).

Step 4: Construct the comprehensive evaluation matrix $X$ by utilizing Eq. (5).

Step 5: Establish and solve the maximum deviation model (Eq. (6)) to derive the weight vector $W$ of criteria.

Step 6: Define thePIS $X^{p}$ and the NIS $X^{n}$ on criteria by Eqs. (11) and (12).

Step 7: Calculate the utility matrix $V$, regret matrix $R$, and rejoicing matrix $H$ of sustainable suppliers, and obtain the perceived utility matrix $U$.

Step 8: Determine the permutation $P_{\tau}$ of sustainable suppliers, and compute the CDI $\phi_{j}^{\tau}\left(S_{\rho}, S_{\eta}\right)$ by Eq. (18).

Step 9: Calculate the weighted concordance/discordance index (WCDI) $\phi^{\tau}\left(S_{\rho}, S_{\eta}\right)$ and the comprehensive concordance/discordance incex (CCDI) $\phi^{\tau}$ by Eq. (19) and Eq. (20), respectively.

Step 10: Determine the optimal ranking order of sustainable suppliers by choosing the permutation with the greatest comprehensive $\operatorname{CDI} \phi^{\tau}$.

\section{NUMERICAL EXAMPLE}

In this section, a case of an automobile manufacturer in China is provided to verify the effectiveness and applicability of the presented method. Since entering the car field in 1996, the automobile manufacturer has achieved rapid development because of flexible operating mechanisms and continuous independent innovation. Therefore, it was named the first batch of national innovative enterprises. Moreover, for four consecutive years, it has entered the top 10 of China's automobile industry. However, the automobile manufacturer is drastically undertaking environmental protection pressure since the implementation of the new Environmental Protection Laws of the People's Republic of China on January 1, 2015. To cut down the environmental protection pressure and improve the competitive advantage simultaneously, the automobile manufacturer has to reevaluate the performance of suppliers from the economic, environmental, and social aspects. To this end, the proposed method in this paper is used for helping the automobile manufacturer to select the best supplier for purchasing the relative components of new automobile product. Ten evaluation criteria relevant to sustainable supplier selection, which collected from previous literatures [5,7], are identified as the total product life cycle 
cost $\left(C_{1}\right)$, quality management $\left(C_{2}\right)$, technology capability $\left(C_{3}\right)$, evironmental management systems $\left(C_{4}\right)$, resource consumption $\left(C_{5}\right)$, eco-design $\left(C_{6}\right)$, green competencies $\left(C_{7}\right)$, occupational health and safety $\left(C_{8}\right)$, information disclosure $\left(C_{9}\right)$, staff envirnmental training $\left(C_{10}\right)$. There are four suppliers $\left(S_{1}, S_{2}, S_{3}, S_{4}\right)$ who needed to be revaluated. The assessment is implemented by a committee of four decision-makers $\left(D_{1}, D_{2}, D_{3}, D_{4}\right)$ who came from different departments of the automobile manufacturer. Decision-makers adopt I class uncertain linguistic term set $S_{I}=$ $\left\{\dot{s}_{0}, \dot{s}_{1}, \dot{s}_{2}, \dot{s}_{3}, \dot{s}_{4}, \dot{s}_{5}, \dot{s}_{6}\right\}$ and II class uncertain linguistic term set $S_{I I}=$ $\left\{\ddot{s}_{0}, \ddot{s}_{1}, \ddot{s}_{2}, \ddot{s}_{3}, \ddot{s}_{4}\right\}$ to give the assessment information of sustainable supplier.

\subsection{Implementation of the Presented Model}

In this subsection, the calculation procedure of the presented approach is described as follows:

Step 1: The evaluation matrices $E_{k}(k=1,2,3,4)$ given by decisionmakers $D_{k}(k=1,2,3,4)$ are shown in Tables $1-4$.

Step 2: Due to the criteria $C_{1}$ and $C_{5}$ are cost criterion, the evaluation values in the matrices $E_{1}, E_{2}, E_{3}$, and $E_{4}$ under the criteria $C_{1}$ and $C_{5}$ need to be normalized to establise normalizied evaluation matrices $X^{1}, X^{2}, X^{3}$, and $X^{4}$.

Step 3: The similarity degree is calculated by using Eq. (3), then weight vector of decision-makers can be obtained $\lambda=$ $(0.259,0.241,0.271,0.229)$.

Step 4: The comprehensive evaluation matrix $X$ can be established by 2-DULWA operator and Eq. (5), and the result is represented in Table 5.

Step 5: Depending on Eqs. (8-12), we can calculate the weight vector $W$ of criteria. The result is $W=(0.086,0.083,0.144,0.091,0.100$, $0.074,0.157,0.078,0.068,0.119)$.

Step 6: The PIS $X^{p}$ and the NIS $X^{n}$ on criteria can be calculated by Eqs. (11) and (12), and are shown in Table 6.

Step 7: Utilizing Eqs. (13-16), we can obtain the utility matrix $V$, regret matrix $R$, rejoicing matrix $H$, and perceived utility matrix $U$, respectively.

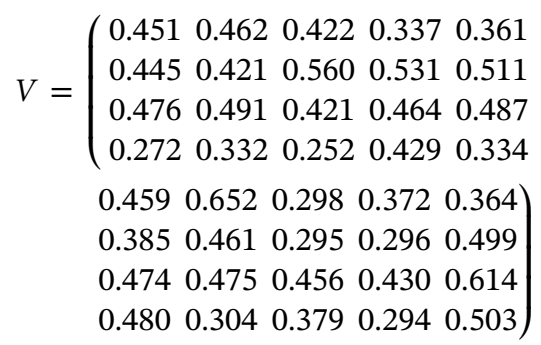

$$
\begin{aligned}
& R=\left(\begin{array}{lllll}
-0.029 & -0.054 & -0.079 & -0.082 & -0.076 \\
-0.031 & -0.067 & -0.035 & -0.021 & -0.029 \\
-0.021 & -0.045 & -0.079 & -0.042 & -0.036 \\
-0.085 & -0.096 & -0.135 & -0.053 & -0.085
\end{array}\right. \\
& \begin{array}{lllll}
-0.045 & 0 & -0.056-0.068 & -0.091
\end{array} \\
& -0.068-0.059-0.057-0.093-0.048 \\
& -0.040-0.055-0.007-0.050-0.012 \\
& -0.038-0.110-0.031-0.094-0.046)
\end{aligned}
$$

$$
\begin{aligned}
H= & \left(\begin{array}{lllll}
0.062 & 0.052 & 0.064 & 0.009 & 0.014 \\
0.060 & 0.041 & 0.102 & 0.066 & 0.058 \\
0.069 & 0.061 & 0.064 & 0.047 & 0.051 \\
0.010 & 0.015 & 0.015 & 0.036 & 0.006 \\
0.027 & 0.117 & 0.006 & 0.055 & 0 \\
0.005 & 0.065 & 0.005 & 0.033 & 0.040 \\
0.032 & 0.068 & 0.052 & 0.071 & 0.072 \\
0.033 & 0.020 & 0.030 & 0.032 & 0.041
\end{array}\right)
\end{aligned}
$$

\begin{tabular}{|c|c|c|c|c|}
\hline Criterion & $S_{1}$ & $S_{2}$ & $S_{3}$ & $S_{4}$ \\
\hline$C_{1}$ & $\left(\left[\dot{s}_{2}, \dot{s}_{3}\right],\left[\ddot{s}_{2}, \ddot{s}_{3}\right]\right)$ & $\left(\left[\dot{s}_{4}, \dot{s}_{5}\right],\left[\ddot{s}_{2}, \ddot{s}_{2}\right]\right)$ & $\left(\left[\dot{s}_{2}, \dot{s}_{5}\right],\left[\ddot{s}_{2}, \ddot{s}_{3}\right]\right)$ & $\left(\left[\dot{s}_{1}, \dot{s}_{3}\right],\left[\ddot{s}_{3}, \ddot{s}_{4}\right]\right)$ \\
\hline$C_{2}$ & $\left(\left[\dot{s}_{1}, \dot{s}_{2}\right],\left[\ddot{s}_{2}, \ddot{s}_{3}\right]\right)$ & $\left(\left[\dot{s}_{3}, \dot{s}_{4}\right],\left[\ddot{s}_{2}, \ddot{s}_{3}\right]\right)$ & $\left(\left[\dot{s}_{4}, \dot{s}_{4}\right],\left[\ddot{s}_{3}, \ddot{s}_{3}\right]\right)$ & $\left(\left[\dot{s}_{3}, \dot{s}_{5}\right],\left[\ddot{s}_{1}, \ddot{s}_{2}\right]\right)$ \\
\hline$C_{3}$ & $\left(\left[\dot{s}_{1}, \dot{s}_{3}\right],\left[\ddot{s}_{2}, \ddot{s}_{3}\right]\right)$ & $\left(\left[\dot{s}_{3}, \dot{s}_{5}\right],\left[\ddot{s}_{2}, \ddot{s}_{4}\right]\right)$ & $\left(\left[\dot{s}_{3}, \dot{s}_{5}\right],\left[\ddot{s}_{2}, \ddot{s}_{4}\right]\right)$ & $\left(\left[\dot{s}_{0}, \dot{s}_{6}\right],\left[\ddot{s}_{0}, \ddot{s}_{2}\right]\right)$ \\
\hline$C_{4}$ & $\left(\left[\dot{s}_{3}, \dot{s}_{5}\right],\left[\ddot{s}_{1}, \ddot{s}_{3}\right]\right)$ & $\left(\left[\dot{s}_{2}, \dot{s}_{3}\right],\left[\ddot{s}_{3}, \ddot{s}_{4}\right]\right)$ & $\left(\left[\dot{s}_{4}, \dot{s}_{4}\right],\left[\ddot{s}_{3}, \ddot{s}_{4}\right]\right)$ & $\left(\left[\dot{s}_{3}, \dot{s}_{4}\right],\left[\ddot{s}_{1}, \ddot{s}_{3}\right]\right)$ \\
\hline$C_{5}$ & $\left(\left[\dot{s}_{3}, \dot{s}_{4}\right],\left[\ddot{s}_{1}, \ddot{s}_{3}\right]\right)$ & $\left(\left[\dot{s}_{2}, \dot{s}_{3}\right],\left[\ddot{s}_{2}, \ddot{s}_{3}\right]\right)$ & $\left(\left[\dot{s}_{2}, \dot{s}_{5}\right],\left[\ddot{s}_{3}, \ddot{s}_{3}\right]\right)$ & $\left(\left[\dot{s}_{5}, \dot{s}_{5}\right],\left[\ddot{s}_{2}, \ddot{s}_{3}\right]\right)$ \\
\hline$C_{6}$ & $\left(\left[\dot{s}_{4}, \dot{s}_{6}\right],\left[\ddot{s}_{2}, \ddot{s}_{4}\right]\right)$ & $\left(\left[\dot{s}_{3}, \dot{s}_{4}\right],\left[\ddot{s}_{2}, \ddot{s}_{3}\right]\right)$ & $\left(\left[\dot{s}_{2}, \dot{s}_{3}\right],\left[\ddot{s}_{2}, \ddot{s}_{3}\right]\right)$ & $\left(\left[\dot{s}_{3}, \dot{s}_{4}\right],\left[\ddot{s}_{0}, \ddot{s}_{4}\right]\right)$ \\
\hline$C_{7}$ & $\left(\left[\dot{s}_{1}, \dot{s}_{2}\right],\left[\ddot{s}_{1}, \ddot{s}_{3}\right]\right)$ & $\left(\left[\dot{s}_{3}, \dot{s}_{3}\right],\left[\ddot{s}_{2}, \ddot{s}_{3}\right]\right)$ & $\left(\left[\dot{s}_{5}, \dot{s}_{5}\right],\left[\ddot{s}_{2}, \ddot{s}_{3}\right]\right)$ & $\left(\left[\dot{s}_{2}, \dot{s}_{4}\right],\left[\ddot{s}_{1}, \ddot{s}_{2}\right]\right)$ \\
\hline$C_{8}$ & $\left(\left[\dot{s}_{1}, \dot{s}_{2}\right],\left[\ddot{s}_{2}, \ddot{s}_{3}\right]\right)$ & $\left(\left[\dot{s}_{4}, \dot{s}_{5}\right],\left[\ddot{s}_{1}, \ddot{s}_{3}\right]\right)$ & $\left(\left[\dot{s}_{1}, \dot{s}_{4}\right],\left[\ddot{s}_{3}, \ddot{s}_{4}\right]\right)$ & $\left(\left[\dot{s}_{3}, \dot{s}_{4}\right],\left[\ddot{s}_{3}, \ddot{s}_{3}\right]\right)$ \\
\hline$C_{9}$ & $\left(\left[\dot{s}_{5}, \dot{s}_{6}\right],\left[\ddot{s}_{2}, \ddot{s}_{4}\right]\right)$ & $\left(\left[\dot{s}_{4}, \dot{s}_{5}\right],\left[\ddot{s}_{2}, \ddot{s}_{3}\right]\right)$ & $\left(\left[\dot{s}_{3}, \dot{s}_{4}\right],\left[\ddot{s}_{3}, \ddot{s}_{4}\right]\right)$ & $\left(\left[\dot{s}_{3}, \dot{s}_{4}\right],\left[\ddot{s}_{1}, \ddot{s}_{1}\right]\right)$ \\
\hline$C_{10}$ & $\left(\left[\dot{s}_{3}, \dot{s}_{5}\right],\left[\ddot{s}_{2}, \ddot{s}_{3}\right]\right)$ & $\left(\left[\dot{s}_{3}, \dot{s}_{4}\right],\left[\ddot{s}_{2}, \ddot{s}_{3}\right]\right)$ & $\left(\left[\dot{s}_{4}, \dot{s}_{6}\right],\left[\ddot{s}_{4}, \ddot{s}_{4}\right]\right)$ & $\left(\left[\dot{s}_{2}, \dot{s}_{3}\right],\left[\ddot{s}_{2}, \ddot{s}_{4}\right]\right)$ \\
\hline
\end{tabular}

$U=\left(\begin{array}{llllll}0.484 & 0.460 & 0.407 & 0.264 & 0.299 \\ 0.474 & 0.395 & 0.626 & 0.576 & 0.540 \\ 0.524 & 0.507 & 0.406 & 0.469 & 0.502 \\ 0.197 & 0.251 & 0.132 & 0.412 & 0.255\end{array}\right.$

$\left.\begin{array}{lllll}0.441 & 0.769 & 0.248 & 0.359 & 0.273\end{array}\right)$

$\begin{array}{lllll}0.322 & 0.467 & 0.243 & 0.236 & 0.491\end{array}$

$\begin{array}{lllll}0.466 & 0.488 & 0.501 & 0.451 & 0.674\end{array}$

$\begin{array}{lllll}0.476 & 0.214 & 0.378 & 0.232 & 0.498\end{array}$

Table 1 2-DULV evaluation matrix $E_{1}$.

DULV, 2-dimensional uncertain linguistic variable. 
Table 2 2-DULV evaluation matrix $E_{2}$.

\begin{tabular}{|c|c|c|c|c|}
\hline Criterion & $S_{1}$ & $S_{2}$ & $S_{3}$ & $S_{4}$ \\
\hline$C_{1}$ & $\left(\left[\dot{s}_{4}, \dot{s}_{6}\right],\left[\ddot{s}_{2}, \ddot{s}_{3}\right]\right)$ & $\left(\left[\dot{s}_{4}, \dot{s}_{5}\right],\left[\ddot{s}_{2}, \ddot{s}_{3}\right]\right)$ & $\left(\left[\dot{s}_{0}, \dot{s}_{1}\right],\left[\ddot{s}_{2}, \ddot{s}_{3}\right]\right)$ & $\left(\left[\dot{s}_{5}, \dot{s}_{6}\right],\left[\ddot{s}_{3}, \ddot{s}_{4}\right]\right)$ \\
\hline$C_{2}$ & $\left(\left[\dot{s}_{4}, \dot{s}_{5}\right],\left[\ddot{s}_{4}, \ddot{s}_{4}\right]\right)$ & $\left(\left[\dot{s}_{1}, \dot{s}_{3}\right],\left[\ddot{s}_{2}, \ddot{s}_{2}\right]\right)$ & $\left(\left[\dot{s}_{4}, \dot{s}_{5}\right],\left[\ddot{s}_{3}, \ddot{s}_{4}\right]\right)$ & $\left(\left[\dot{s}_{5}, \dot{s}_{6}\right],\left[\ddot{s}_{1}, \ddot{s}_{3}\right]\right)$ \\
\hline$C_{3}$ & $\left(\left[\dot{s}_{5}, \dot{s}_{6}\right],\left[\ddot{s}_{2}, \ddot{s}_{3}\right]\right)$ & $\left(\left[\dot{s}_{5}, \dot{s}_{6}\right],\left[\ddot{s}_{3}, \ddot{s}_{4}\right]\right)$ & $\left(\left[\dot{s}_{1}, \dot{s}_{2}\right],\left[\ddot{s}_{2}, \ddot{s}_{3}\right]\right)$ & $\left(\left[\dot{s}_{0}, \dot{s}_{1}\right],\left[\ddot{s}_{1}, \ddot{s}_{2}\right]\right)$ \\
\hline$C_{4}$ & $\left(\left[\dot{s}_{0}, \dot{s}_{1}\right],\left[\ddot{s}_{1}, \ddot{s}_{3}\right]\right)$ & $\left(\left[\dot{s}_{5}, \dot{s}_{6}\right],\left[\ddot{s}_{3}, \ddot{s}_{3}\right]\right)$ & $\left(\left[\dot{s}_{0}, \dot{s}_{1}\right],\left[\ddot{s}_{2}, \ddot{s}_{3}\right]\right)$ & $\left(\left[\dot{s}_{1}, \dot{s}_{2}\right],\left[\ddot{s}_{2}, \ddot{s}_{4}\right]\right)$ \\
\hline$C_{5}$ & $\left(\left[\dot{s}_{0}, \dot{s}_{1}\right],\left[\ddot{s}_{1}, \ddot{s}_{3}\right]\right)$ & $\left(\left[\dot{s}_{5}, \dot{s}_{6}\right],\left[\ddot{s}_{3}, \ddot{s}_{4}\right]\right)$ & $\left(\left[\dot{s}_{0}, \dot{s}_{1}\right],\left[\ddot{s}_{1}, \ddot{s}_{2}\right]\right)$ & $\left(\left[\dot{s}_{1}, \dot{s}_{3}\right],\left[\ddot{s}_{2}, \ddot{s}_{3}\right]\right)$ \\
\hline$C_{6}$ & $\left(\left[\dot{s}_{4}, \dot{s}_{6}\right],\left[\ddot{s}_{2}, \ddot{s}_{4}\right]\right)$ & $\left(\left[\dot{s}_{1}, \dot{s}_{2}\right],\left[\ddot{s}_{2}, \ddot{s}_{3}\right]\right)$ & $\left(\left[\dot{s}_{4}, \dot{s}_{5}\right],\left[\ddot{s}_{3}, \ddot{s}_{4}\right]\right)$ & $\left(\left[\dot{s}_{1}, \dot{s}_{3}\right],\left[\ddot{s}_{0}, \ddot{s}_{1}\right]\right)$ \\
\hline$C_{7}$ & $\left(\left[\dot{s}_{5}, \dot{s}_{6}\right],\left[\ddot{s}_{2}, \ddot{s}_{3}\right]\right)$ & $\left(\left[\dot{s}_{4}, \dot{s}_{5}\right],\left[\ddot{s}_{3}, \ddot{s}_{3}\right]\right)$ & $\left(\left[\dot{s}_{0}, \dot{s}_{1}\right],\left[\ddot{s}_{4}, \ddot{s}_{4}\right]\right)$ & $\left(\left[\dot{s}_{4}, \dot{s}_{5}\right],\left[\ddot{s}_{0}, \ddot{s}_{2}\right]\right)$ \\
\hline$C_{8}$ & $\left(\left[\dot{s}_{5}, \dot{s}_{5}\right],\left[\ddot{s}_{2}, \ddot{s}_{3}\right]\right)$ & $\left(\left[\dot{s}_{0}, \dot{s}_{1}\right],\left[\ddot{s}_{2}, \ddot{s}_{3}\right]\right)$ & $\left(\left[\dot{s}_{1}, \dot{s}_{2}\right],\left[\ddot{s}_{3}, \ddot{s}_{4}\right]\right)$ & $\left(\left[\dot{s}_{3}, \dot{s}_{5}\right],\left[\ddot{s}_{3}, \ddot{s}_{3}\right]\right)$ \\
\hline$C_{9}$ & $\left(\left[\dot{s}_{1}, \dot{s}_{1}\right],\left[\ddot{s}_{2}, \ddot{s}_{3}\right]\right)$ & $\left(\left[\dot{s}_{4}, \dot{s}_{5}\right],\left[\ddot{s}_{2}, \ddot{s}_{3}\right]\right)$ & $\left(\left[\dot{s}_{4}, \dot{s}_{4}\right],\left[\ddot{s}_{3}, \ddot{s}_{4}\right]\right)$ & $\left(\left[\dot{s}_{5}, \dot{s}_{6}\right],\left[\ddot{s}_{1}, \ddot{s}_{2}\right]\right)$ \\
\hline$C_{10}$ & $\left(\left[\dot{s}_{4}, \dot{s}_{5}\right],\left[\ddot{s}_{2}, \ddot{s}_{3}\right]\right)$ & $\left(\left[\dot{s}_{4}, \dot{s}_{4}\right],\left[\ddot{s}_{2}, \ddot{s}_{3}\right]\right)$ & $\left(\left[\dot{s}_{1}, \dot{s}_{2}\right],\left[\ddot{s}_{3}, \ddot{s}_{4}\right]\right)$ & $\left(\left[\dot{s}_{2}, \dot{s}_{4}\right],\left[\ddot{s}_{2}, \ddot{s}_{3}\right]\right)$ \\
\hline
\end{tabular}

DULV, 2-dimensional uncertain linguistic variable.

Table 3 2-DULV evaluation matrix $E_{3}$.

\begin{tabular}{|c|c|c|c|c|}
\hline Criterion & $S_{1}$ & $S_{2}$ & $S_{3}$ & $S_{4}$ \\
\hline$C_{1}$ & $\left(\left[\dot{s}_{3}, \dot{s}_{4}\right],\left[\ddot{s}_{2}, \ddot{s}_{3}\right]\right)$ & $\left(\left[\dot{s}_{0}, \dot{s}_{2}\right],\left[\ddot{s}_{1}, \ddot{s}_{2}\right]\right)$ & $\left(\left[\dot{s}_{0}, \dot{s}_{2}\right],\left[\ddot{s}_{2}, \ddot{s}_{3}\right]\right)$ & $\left(\left[\dot{s}_{4}, \dot{s}_{5}\right],\left[\ddot{s}_{3}, \ddot{s}_{4}\right]\right)$ \\
\hline$C_{2}$ & $\left(\left[\dot{s}_{2}, \dot{s}_{3}\right],\left[\ddot{s}_{2}, \ddot{s}_{3}\right]\right)$ & $\left(\left[\dot{s}_{3}, \dot{s}_{4}\right],\left[\ddot{s}_{3}, \ddot{s}_{3}\right]\right)$ & $\left(\left[\dot{s}_{3}, \dot{s}_{4}\right],\left[\ddot{s}_{3}, \ddot{s}_{3}\right]\right)$ & $\left(\left[\dot{s}_{1}, \dot{s}_{2}\right],\left[\ddot{s}_{3}, \ddot{s}_{3}\right]\right)$ \\
\hline$C_{3}$ & $\left(\left[\dot{s}_{1}, \dot{s}_{2}\right],\left[\ddot{s}_{4}, \ddot{s}_{4}\right]\right)$ & $\left(\left[\dot{s}_{2}, \dot{s}_{3}\right],\left[\ddot{s}_{3}, \ddot{s}_{4}\right]\right)$ & $\left(\left[\dot{s}_{4}, \dot{s}_{6}\right],\left[\ddot{s}_{2}, \ddot{s}_{3}\right]\right)$ & $\left(\left[\dot{s}_{2}, \dot{s}_{3}\right],\left[\ddot{s}_{2}, \ddot{s}_{3}\right]\right)$ \\
\hline$C_{4}$ & $\left(\left[\dot{s}_{2}, \dot{s}_{4}\right],\left[\ddot{s}_{2}, \ddot{s}_{3}\right]\right)$ & $\left(\left[\dot{s}_{3}, \dot{s}_{4}\right],\left[\ddot{s}_{2}, \ddot{s}_{3}\right]\right)$ & $\left(\left[\dot{s}_{2}, \dot{s}_{3}\right],\left[\ddot{s}_{3}, \ddot{s}_{4}\right]\right)$ & $\left(\left[\dot{s}_{2}, \dot{s}_{3}\right],\left[\ddot{s}_{3}, \ddot{s}_{4}\right]\right)$ \\
\hline$C_{5}$ & $\left(\left[\dot{s}_{2}, \dot{s}_{3}\right],\left[\ddot{s}_{3}, \ddot{s}_{3}\right]\right)$ & $\left(\left[\dot{s}_{1}, \dot{s}_{2}\right],\left[\ddot{s}_{3}, \ddot{s}_{3}\right]\right)$ & $\left(\left[\dot{s}_{3}, \dot{s}_{4}\right],\left[\ddot{s}_{3}, \ddot{s}_{3}\right]\right)$ & $\left(\left[\dot{s}_{4}, \dot{s}_{5}\right],\left[\ddot{s}_{3}, \ddot{s}_{3}\right]\right)$ \\
\hline$C_{6}$ & $\left(\left[\dot{s}_{2}, \dot{s}_{4}\right],\left[\ddot{s}_{2}, \ddot{s}_{3}\right]\right)$ & $\left(\left[\dot{s}_{3}, \dot{s}_{4}\right],\left[\ddot{s}_{3}, \ddot{s}_{4}\right]\right)$ & $\left(\left[\dot{s}_{2}, \dot{s}_{4}\right],\left[\ddot{s}_{2}, \ddot{s}_{4}\right]\right)$ & $\left(\left[\dot{s}_{4}, \dot{s}_{5}\right],\left[\ddot{s}_{1}, \ddot{s}_{2}\right]\right)$ \\
\hline$C_{7}$ & $\left(\left[\dot{s}_{3}, \dot{s}_{4}\right],\left[\ddot{s}_{4}, \ddot{s}_{4}\right]\right)$ & $\left(\left[\dot{s}_{2}, \dot{s}_{4}\right],\left[\ddot{s}_{3}, \ddot{s}_{4}\right]\right)$ & $\left(\left[\dot{s}_{3}, \dot{s}_{3}\right],\left[\ddot{s}_{2}, \ddot{s}_{3}\right]\right)$ & $\left(\left[\dot{s}_{0}, \dot{s}_{2}\right],\left[\ddot{s}_{1}, \ddot{s}_{3}\right]\right)$ \\
\hline$C_{8}$ & $\left(\left[\dot{s}_{3}, \dot{s}_{3}\right],\left[\ddot{s}_{2}, \ddot{s}_{2}\right]\right)$ & $\left(\left[\dot{s}_{4}, \dot{s}_{5}\right],\left[\ddot{s}_{2}, \ddot{s}_{2}\right]\right)$ & $\left(\left[\dot{s}_{5}, \dot{s}_{5}\right],\left[\ddot{s}_{2}, \ddot{s}_{2}\right]\right)$ & $\left(\left[\dot{s}_{2}, \dot{s}_{3}\right],\left[\ddot{s}_{2}, \ddot{s}_{2}\right]\right)$ \\
\hline$C_{9}$ & $\left(\left[\dot{s}_{2}, \dot{s}_{3}\right],\left[\ddot{s}_{3}, \ddot{s}_{4}\right]\right)$ & $\left(\left[\dot{s}_{1}, \dot{s}_{3}\right],\left[\ddot{s}_{0}, \ddot{s}_{2}\right]\right)$ & $\left(\left[\dot{s}_{3}, \dot{s}_{4}\right],\left[\ddot{s}_{1}, \ddot{s}_{2}\right]\right)$ & $\left(\left[\dot{s}_{2}, \dot{s}_{3}\right],\left[\ddot{s}_{0}, \ddot{s}_{2}\right]\right)$ \\
\hline$C_{10}$ & $\left(\left[\dot{s}_{2}, \dot{s}_{4}\right],\left[\ddot{s}_{2}, \ddot{s}_{3}\right]\right)$ & $\left(\left[\dot{s}_{4}, \dot{s}_{5}\right],\left[\ddot{s}_{3}, \ddot{s}_{4}\right]\right)$ & $\left(\left[\dot{s}_{3}, \dot{s}_{6}\right],\left[\ddot{s}_{4}, \ddot{s}_{4}\right]\right)$ & $\left(\left[\dot{s}_{3}, \dot{s}_{4}\right],\left[\ddot{s}_{3}, \ddot{s}_{3}\right]\right)$ \\
\hline
\end{tabular}

DULV, 2-dimensional uncertain linguistic variable.

Table 4 2-DULV evaluation matrix $E_{4}$.

\begin{tabular}{|c|c|c|c|c|}
\hline Criterion & $S_{1}$ & $S_{2}$ & $S_{3}$ & $S_{4}$ \\
\hline$C_{1}$ & $\left(\left[\dot{s}_{0}, \dot{s}_{1}\right],\left[\ddot{s}_{3}, \ddot{s}_{4}\right]\right)$ & $\left(\left[\dot{s}_{1}, \dot{s}_{2}\right],\left[\ddot{s}_{3}, \ddot{s}_{4}\right]\right)$ & $\left(\left[\dot{s}_{5}, \dot{s}_{6}\right],\left[\ddot{s}_{2}, \ddot{s}_{4}\right]\right)$ & $\left(\left[\dot{s}_{6}, \dot{s}_{6}\right],\left[\ddot{s}_{3}, \ddot{s}_{3}\right]\right)$ \\
\hline$C_{2}$ & $\left(\left[\dot{s}_{0}, \dot{s}_{3}\right],\left[\ddot{s}_{1}, \ddot{s}_{3}\right]\right)$ & $\left(\left[\dot{s}_{5}, \dot{s}_{6}\right],\left[\ddot{s}_{1}, \ddot{s}_{3}\right]\right)$ & $\left(\left[\dot{s}_{0}, \dot{s}_{1}\right],\left[\ddot{s}_{1}, \ddot{s}_{3}\right]\right)$ & $\left(\left[\dot{s}_{1}, \dot{s}_{1}\right],\left[\ddot{s}_{1}, \ddot{s}_{3}\right]\right)$ \\
\hline$C_{3}$ & $\left(\left[\dot{s}_{0}, \dot{s}_{0}\right],\left[\ddot{s}_{4}, \ddot{s}_{4}\right]\right)$ & $\left(\left[\dot{s}_{2}, \dot{s}_{5}\right],\left[\ddot{s}_{1}, \ddot{s}_{3}\right]\right)$ & $\left(\left[\dot{s}_{1}, \dot{s}_{2}\right],\left[\ddot{s}_{1}, \ddot{s}_{3}\right]\right)$ & $\left(\left[\dot{s}_{4}, \dot{s}_{6}\right],\left[\ddot{s}_{1}, \ddot{s}_{3}\right]\right)$ \\
\hline$C_{4}$ & $\left(\left[\dot{s}_{5}, \dot{s}_{6}\right],\left[\ddot{s}_{1}, \ddot{s}_{3}\right]\right)$ & $\left(\left[\dot{s}_{0}, \dot{s}_{0}\right],\left[\ddot{s}_{4}, \ddot{s}_{4}\right]\right)$ & $\left(\left[\dot{s}_{5}, \dot{s}_{6}\right],\left[\ddot{s}_{1}, \ddot{s}_{3}\right]\right)$ & $\left(\left[\dot{s}_{4}, \dot{s}_{5}\right],\left[\ddot{s}_{2}, \ddot{s}_{3}\right]\right)$ \\
\hline$C_{5}$ & $\left(\left[\dot{s}_{5}, \dot{s}_{6}\right],\left[\ddot{s}_{2}, \ddot{s}_{3}\right]\right)$ & $\left(\left[\dot{s}_{1}, \dot{s}_{1}\right],\left[\ddot{s}_{2}, \ddot{s}_{3}\right]\right)$ & $\left(\left[\dot{s}_{6}, \dot{s}_{6}\right],\left[\ddot{s}_{4}, \ddot{s}_{4}\right]\right)$ & $\left(\left[\dot{s}_{1}, \dot{s}_{2}\right],\left[\ddot{s}_{1}, \ddot{s}_{3}\right]\right)$ \\
\hline$C_{6}$ & $\left(\left[\dot{s}_{0}, \dot{s}_{1}\right],\left[\ddot{s}_{2}, \ddot{s}_{3}\right]\right)$ & $\left(\left[\dot{s}_{1}, \dot{s}_{2}\right],\left[\ddot{s}_{2}, \ddot{s}_{3}\right]\right)$ & $\left(\left[\dot{s}_{3}, \dot{s}_{4}\right],\left[\ddot{s}_{1}, \ddot{s}_{3}\right]\right)$ & $\left(\left[\dot{s}_{0}, \dot{s}_{0}\right],\left[\ddot{s}_{4}, \ddot{s}_{4}\right]\right)$ \\
\hline$C_{7}$ & $\left(\left[\dot{s}_{4}, \dot{s}_{5}\right],\left[\ddot{s}_{2}, \ddot{s}_{3}\right]\right)$ & $\left(\left[\dot{s}_{1}, \dot{s}_{2}\right],\left[\ddot{s}_{2}, \ddot{s}_{3}\right]\right)$ & $\left(\left[\dot{s}_{1}, \dot{s}_{2}\right],\left[\ddot{s}_{2}, \ddot{s}_{3}\right]\right)$ & $\left(\left[\dot{s}_{5}, \dot{s}_{6}\right],\left[\ddot{s}_{2}, \ddot{s}_{3}\right]\right)$ \\
\hline$C_{8}$ & $\left(\left[\dot{s}_{0}, \dot{s}_{2}\right],\left[\ddot{s}_{1}, \ddot{s}_{3}\right]\right)$ & $\left(\left[\dot{s}_{0}, \dot{s}_{1}\right],\left[\ddot{s}_{2}, \ddot{s}_{3}\right]\right)$ & $\left(\left[\dot{s}_{2}, \dot{s}_{4}\right],\left[\ddot{s}_{1}, \ddot{s}_{3}\right]\right)$ & $\left(\left[\dot{s}_{2}, \dot{s}_{4}\right],\left[\ddot{s}_{0}, \ddot{s}_{2}\right]\right)$ \\
\hline$C_{9}$ & $\left(\left[\dot{s}_{0}, \dot{s}_{1}\right],\left[\ddot{s}_{2}, \ddot{s}_{3}\right]\right)$ & $\left(\left[\dot{s}_{0}, \dot{s}_{1}\right],\left[\ddot{s}_{1}, \ddot{s}_{3}\right]\right)$ & $\left(\left[\dot{s}_{0}, \dot{s}_{1}\right],\left[\ddot{s}_{1}, \ddot{s}_{3}\right]\right)$ & $\left(\left[\dot{s}_{5}, \dot{s}_{6}\right],\left[\ddot{s}_{1}, \ddot{s}_{3}\right]\right)$ \\
\hline$C_{10}$ & $\left(\left[\dot{s}_{0}, \dot{s}_{1}\right],\left[\ddot{s}_{2}, \ddot{s}_{3}\right]\right)$ & $\left(\left[\dot{s}_{1}, \dot{s}_{2}\right],\left[\ddot{s}_{2}, \ddot{s}_{4}\right]\right)$ & $\left(\left[\dot{s}_{2}, \dot{s}_{3}\right],\left[\ddot{s}_{1}, \ddot{s}_{3}\right]\right)$ & $\left(\left[\dot{s}_{4}, \dot{s}_{6}\right],\left[\ddot{s}_{2}, \ddot{s}_{4}\right]\right)$ \\
\hline
\end{tabular}

DULV, 2-dimensional uncertain linguistic variable.

Step 8: Define the permutation $P_{\tau}$ of sustainable suppliers, and calculate the CDI for all permutation. Owing to $m=4$, there is $24(4 !=6)$ permutation of the sorting for all sustainable suppliers, which are represented in Table 7.

Then the CDI $\phi_{j}^{\tau}\left(S_{\rho}, S_{\eta}\right)$ can be calculated by Eq. (18). Take the permutation $P_{1}$ as an example, the results of CDI for $P_{1}$ are shown in Table 8.

Step 9: According to Eq. (19), the WCDIs for all permutations are listed in Table 9. Then, using the Eq. (20), the CCDI for all permutations are shown in Table 10.

Step 10: The optimal permutation can be obtained by descending order of CCDI value, that is, permutation $P_{15}$. Consequently, the priority of sustainable suppliers is $S_{3}>S_{2}>S_{1}>S_{4}$. In other words, $S_{3}$ is the best sustainable supplier.

\subsection{Sensitivity Analysis}

To illustrate the influence of different risk aversion coefficient $\alpha$ and regret aversion coefficient $\delta$ on the CCDI value, a sensitivity analysis with respect to parameter $\alpha$ and $\delta$ is carried out in this subsection. The corresponding results are shown in Figures 2 and 3.

From Figure 2, we can know that the CCDI values of all permutations have changed with different $\alpha$ values. With the increase of risk aversion coefficient $\alpha$, the CCDI values less than zero are becoming smaller and smaller, and the CCDI values greater than zero are getting bigger and bigger. But it's noted that the permutation $P_{15}$ has the greatest CCDI value all the time. In other words, the optimal ranking of all sustainable suppliers has not changed, that is, $S_{3}>S_{2}>S_{1}>S_{4}$. From Figure 3, similar to the situation above, we find that the positive CCDI values are becoming 
Table 5 The comprehensive evaluation matrix $X$.

\begin{tabular}{|c|c|c|c|c|}
\hline Criterion & $S_{1}$ & $S_{2}$ & $S_{3}$ & $S_{4}$ \\
\hline$C_{1}$ & $\left(\left[\dot{s}_{2.464}, \dot{s}_{3.705}\right],\left[\ddot{s}_{2.294}, \ddot{s}_{4.000}\right]\right)$ & $\left(\left[\dot{s}_{2.500}, \dot{s}_{3.771}\right],\left[\ddot{s}_{2.095}, \ddot{s}_{4.000}\right]\right)$ & $\left(\left[\dot{s}_{2.548}, \dot{s}_{4.337}\right],\left[\ddot{s}_{2.000}, \ddot{s}_{4.000}\right]\right)$ & $\left(\left[\dot{s}_{1.048}, \dot{s}_{2.078}\right],\left[\ddot{s}_{3.000}, \ddot{s}_{4.000}\right]\right)$ \\
\hline$C_{2}$ & $\left(\left[\dot{s}_{1.765}, \dot{s}_{3.223}\right],\left[\ddot{s}_{4.000}, \ddot{s}_{4.000}\right]\right)$ & $\left(\left[\dot{s}_{2.976}, \dot{s}_{4.217}\right],\left[\ddot{s}_{2.181}, \ddot{s}_{2.818}\right]\right)$ & $\left(\left[\dot{s}_{2.813}, \dot{s}_{3.554}\right],\left[\ddot{s}_{2.714}, \ddot{s}_{4.000}\right]\right)$ & $\left(\left[\dot{s}_{2.482}, \dot{s}_{3.512}\right],\left[\ddot{s}_{1.772}, \ddot{s}_{2.803}\right]\right)$ \\
\hline$C_{3}$ & $\left(\left[\dot{s}_{1.735}, \dot{s}_{2.765}\right],\left[\ddot{s}_{4.000}, \ddot{s}_{4.000}\right]\right)$ & $\left(\left[\dot{s}_{2.982}, \dot{s}_{4.699}\right],\left[\ddot{s}_{2.461}, \ddot{s}_{4.000}\right]\right)$ & $\left(\left[\dot{s}_{2.331}, \dot{s}_{3.861}\right],\left[\ddot{s}_{1.805}, \ddot{s}_{4.000}\right]\right)$ & $\left(\left[\dot{s}_{1.458}, \dot{s}_{3.982}\right],\left[\ddot{s}_{1.104}, \ddot{s}_{2.586}\right]\right)$ \\
\hline$C_{4}$ & $\left(\left[\dot{s}_{2.464}, \dot{s}_{3.994}\right],\left[\ddot{s}_{1.312}, \ddot{s}_{3.000}\right]\right)$ & $\left(\left[\dot{s}_{2.536}, \dot{s}_{3.307}\right],\left[\ddot{s}_{4.000}, \ddot{s}_{4.000}\right]\right)$ & $\left(\left[\dot{s}_{2.723}, \dot{s}_{3.464}\right],\left[\ddot{s}_{2.480}, \ddot{s}_{4.000}\right]\right)$ & $\left(\left[\dot{s}_{2.476}, \dot{s}_{3.476}\right],\left[\ddot{s}_{2.159}, \ddot{s}_{4.000}\right]\right)$ \\
\hline$C_{5}$ & $\left(\left[\dot{s}_{2.536}, \dot{s}_{3.536}\right],\left[\ddot{s}_{1.970}, \ddot{s}_{3.000}\right]\right)$ & $\left(\left[\dot{s}_{3.006}, \dot{s}_{3.777}\right],\left[\ddot{s}_{2.598}, \ddot{s}_{4.000}\right]\right)$ & $\left(\left[\dot{s}_{2.006}, \dot{s}_{3.295}\right],\left[\ddot{s}_{4.000}, \ddot{s}_{4.000}\right]\right)$ & $\left(\left[\dot{s}_{2.169}, \dot{s}_{3.151}\right],\left[\ddot{s}_{2.181}, \ddot{s}_{3.000}\right]\right)$ \\
\hline$C_{6}$ & $\left(\left[\dot{s}_{2.542}, \dot{s}_{4.054}\right],\left[\ddot{s}_{2.000}, \ddot{s}_{4.000}\right]\right)$ & $\left(\left[\dot{s}_{2.060}, \dot{s}_{3.060}\right],\left[\ddot{s}_{2.343}, \ddot{s}_{4.000}\right]\right)$ & $\left(\left[\dot{s}_{2.711}, \dot{s}_{3.982}\right],\left[\ddot{s}_{2.143}, \ddot{s}_{4.000}\right]\right)$ & $\left(\left[\dot{s}_{2.102}, \dot{s}_{3.114}\right],\left[\ddot{s}_{4.000}, \ddot{s}_{4.000}\right]\right)$ \\
\hline$C_{7}$ & $\left(\left[\dot{s}_{3.193}, \dot{s}_{4.193}\right],\left[\ddot{s}_{4.000}, \ddot{s}_{4.000}\right]\right)$ & $\left(\left[\dot{s}_{2.512}, \dot{s}_{3.524}\right],\left[\ddot{s}_{2.598}, \ddot{s}_{4.000}\right]\right)$ & $\left(\left[\dot{s}_{2.337}, \dot{s}_{2.807}\right],\left[\ddot{s}_{4.000}, \ddot{s}_{4.000}\right]\right)$ & $\left(\left[\dot{s}_{2.627}, \dot{s}_{4.157}\right],\left[\ddot{s}_{1.070}, \ddot{s}_{2.586}\right]\right)$ \\
\hline$C_{8}$ & $\left(\left[\dot{s}_{2.277}, \dot{s}_{2.994}\right],\left[\ddot{s}_{1.805}, \ddot{s}_{2.739}\right]\right)$ & $\left(\left[\dot{s}_{2.120}, \dot{s}_{3.120}\right],\left[\ddot{s}_{1.779}, \ddot{s}_{2.793}\right]\right)$ & $\left(\left[\dot{s}_{2.313}, \dot{s}_{3.789}\right],\left[\ddot{s}_{2.448}, \ddot{s}_{4.000}\right]\right)$ & $\left(\left[\dot{s}_{2.500}, \dot{s}_{3.970}\right],\left[\ddot{s}_{2.343}, \ddot{s}_{2.586}\right]\right)$ \\
\hline$C_{9}$ & $\left(\left[\dot{s}_{2.078}, \dot{s}_{2.837}\right],\left[\ddot{s}_{2.343}, \ddot{s}_{4.000}\right]\right)$ & $\left(\left[\dot{s}_{2.271}, \dot{s}_{3.542}\right],\left[\ddot{s}_{1.352}, \ddot{s}_{2.793}\right]\right)$ & $\left(\left[\dot{s}_{2.554}, \dot{s}_{3.313}\right],\left[\ddot{s}_{2.268}, \ddot{s}_{4.000}\right]\right)$ & $\left(\left[\dot{s}_{3.669}, \dot{s}_{4.669}\right],\left[\ddot{s}_{0.757}, \ddot{s}_{2.105}\right]\right)$ \\
\hline$C_{10}$ & $\left(\left[\dot{s}_{2.283}, \dot{s}_{3.183}\right],\left[\ddot{s}_{2.000}, \ddot{s}_{3.000}\right]\right)$ & $\left(\left[\dot{s}_{3.054}, \dot{s}_{3.813}\right],\left[\ddot{s}_{2.343}, \ddot{s}_{4.000}\right]\right)$ & $\left(\left[\dot{s}_{2.548}, \dot{s}_{4.349}\right],\left[\ddot{s}_{4.000}, \ddot{s}_{4.000}\right]\right)$ & $\left(\left[\dot{s}_{2.729}, \dot{s}_{4.199}\right],\left[\ddot{s}_{2.343}, \ddot{s}_{4.000}\right]\right)$ \\
\hline
\end{tabular}

Table 6 The positive/negative ideal solution $X^{P} / X^{n}$.

\begin{tabular}{lllc}
\hline Criterion & \multicolumn{1}{c}{ PIS } & Criterion & NIS \\
\hline$C_{1}$ & $\left(\left[\dot{s}_{2.548}, \dot{s}_{4.337}\right],\left[\ddot{s}_{3.000}, \ddot{s}_{4.000}\right]\right)$ & $C_{1}$ & $\left(\left[\dot{s}_{1.048}, \dot{s}_{2.078}\right],\left[\ddot{s}_{2.000}, \ddot{s}_{4.000}\right]\right)$ \\
$C_{2}$ & $\left(\left[\dot{s}_{2.976}, \dot{s}_{4.217}\right],\left[\ddot{s}_{4.000}, \ddot{s}_{4.000}\right]\right)$ & $C_{2}$ & $\left(\left[\dot{s}_{1.765}, \dot{s}_{3.223}\right],\left[\ddot{s}_{1.772}, \ddot{s}_{2.803}\right]\right)$ \\
$C_{3}$ & $\left(\left[\dot{s}_{2.982}, \dot{s}_{4.699}\right],\left[\ddot{s}_{4.000}, \ddot{s}_{4.000}\right]\right)$ & $C_{3}$ & $\left(\left[\dot{s}_{1.458}, \dot{s}_{2.765}\right],\left[\ddot{s}_{1.104}, \ddot{s}_{2.586}\right]\right)$ \\
$C_{4}$ & $\left(\left[\dot{s}_{2.723}, \dot{s}_{3.994}\right],\left[\ddot{s}_{4.000}, \ddot{s}_{4.000}\right]\right)$ & $C_{4}$ & $\left(\left[\dot{s}_{2.464}, \dot{s}_{3.307}\right],\left[\ddot{s}_{1.312}, \ddot{s}_{3.000}\right]\right)$ \\
$C_{5}$ & $\left(\left[\dot{s}_{3.006}, \dot{s}_{3.777}\right],\left[\ddot{s}_{4.000}, \ddot{s}_{4.000}\right]\right)$ & $C_{5}$ & $\left(\left[\dot{s}_{2.006}, \dot{s}_{3.151}\right],\left[\ddot{s}_{1.970}, \ddot{s}_{3.000}\right]\right)$ \\
$C_{6}$ & $\left(\left[\dot{s}_{2.711}, \dot{s}_{4.054}\right],\left[\ddot{s}_{4.000}, \ddot{s}_{4.000}\right]\right)$ & $C_{6}$ & $\left(\left[\dot{s}_{2.060}, \dot{s}_{3.060}\right],\left[\ddot{s}_{2.000}, \ddot{s}_{4.000}\right]\right)$ \\
$C_{7}$ & $\left(\left[\dot{s}_{3.193}, \dot{s}_{4.193}\right],\left[\ddot{s}_{4.000}, \ddot{s}_{4.000}\right]\right)$ & $C_{7}$ & $\left(\left[\dot{s}_{2.337}, \dot{s}_{2.807}\right],\left[\ddot{s}_{1.070}, \ddot{s}_{2.586}\right]\right)$ \\
$C_{8}$ & $\left(\left[\dot{s}_{2.500}, \dot{s}_{3.970}\right],\left[\ddot{s}_{2.448}, \ddot{s}_{4.000}\right]\right)$ & $C_{8}$ & $\left(\left[\dot{s}_{2.120}, \dot{s}_{2.994}\right],\left[\ddot{s}_{1.779}, \ddot{s}_{2.586}\right]\right)$ \\
$C_{9}$ & $\left(\left[\dot{s}_{3.669}, \dot{s}_{4.669}\right],\left[\ddot{s}_{2.343}, \ddot{s}_{4.000}\right]\right)$ & $C_{9}$ & $\left(\left[\dot{s}_{2.078}, \dot{s}_{2.837}\right],\left[\ddot{s}_{0.757}, \ddot{s}_{2.105}\right]\right)$ \\
$C_{10}$ & $\left(\left[\dot{s}_{3.054}, \dot{s}_{4.349}\right],\left[\ddot{s}_{4.000}, \ddot{s}_{4.000}\right]\right)$ & $C_{10}$ & $\left(\left[\dot{s}_{2.283}, \dot{s}_{3.813}\right],\left[\ddot{s}_{2.000}, \ddot{s}_{3.000}\right]\right)$ \\
\hline
\end{tabular}

PIS, positive ideal solution; NIS, negative ideal solution.

Table 7 Permutation of all sustainable suppliers.

\begin{tabular}{lccccccc}
\hline $\boldsymbol{P}_{\boldsymbol{\tau}}$ & Permutation & $\boldsymbol{P}_{\boldsymbol{\tau}}$ & Permutation & $\boldsymbol{P}_{\tau}$ & Permutation & $\boldsymbol{P}_{\boldsymbol{\tau}}$ & Permutation \\
\hline$P_{1}$ & $\left(S_{1}, S_{2}, S_{3}, S_{4}\right)$ & $P_{2}$ & $\left(S_{1}, S_{2}, S_{4}, S_{3}\right)$ & $P_{3}$ & $\left(S_{1}, S_{3}, S_{2}, S_{4}\right)$ & $P_{4}$ & $\left(S_{1}, S_{3}, S_{4}, S_{2}\right)$ \\
$P_{5}$ & $\left(S_{1}, S_{4}, S_{2}, S_{3}\right)$ & $P_{6}$ & $\left(S_{1}, S_{4}, S_{3}, S_{2}\right)$ & $P_{7}$ & $\left(S_{2}, S_{1}, S_{3}, S_{4}\right)$ & $P_{8}$ & $\left(S_{2}, S_{1}, S_{4}, S_{3}\right)$ \\
$P_{9}$ & $\left(S_{2}, S_{3}, S_{1}, S_{4}\right)$ & $P_{10}$ & $\left(S_{2}, S_{3}, S_{4}, S_{1}\right)$ & $P_{11}$ & $\left(S_{2}, S_{4}, S_{1}, S_{3}\right)$ & $P_{12}$ & $\left(S_{2}, S_{4}, S_{3}, S_{1}\right)$ \\
$P_{13}$ & $\left(S_{3}, S_{1}, S_{2}, S_{4}\right)$ & $P_{14}$ & $\left(S_{3}, S_{1}, S_{4}, S_{2}\right)$ & $P_{15}$ & $\left(S_{3}, S_{2}, S_{1}, S_{4}\right)$ & $P_{16}$ & $\left(S_{3}, S_{2}, S_{4}, S_{1}\right)$ \\
$P_{17}$ & $\left(S_{3}, S_{4}, S_{1}, S_{2}\right)$ & $P_{18}$ & $\left(S_{3}, S_{4}, S_{2}, S_{1}\right)$ & $P_{19}$ & $\left(S_{4}, S_{1}, S_{2}, S_{3}\right)$ & $P_{20}$ & $\left(S_{4}, S_{1}, S_{3}, S_{2}\right)$ \\
$P_{21}$ & $\left(S_{4}, S_{2}, S_{1}, S_{3}\right)$ & $P_{22}$ & $\left(S_{4}, S_{2}, S_{3}, S_{1}\right)$ & $P_{23}$ & $\left(S_{4}, S_{3}, S_{1}, S_{2}\right)$ & $P_{24}$ & $\left(S_{4}, S_{3}, S_{2}, S_{1}\right)$ \\
\hline
\end{tabular}

Table 8 The results of CDI for permutation $P_{1}$.

\begin{tabular}{lcccccrrrrr}
\hline $\boldsymbol{P}_{\mathbf{1}}$ & $\boldsymbol{C}_{\mathbf{1}}$ & \multicolumn{1}{c}{$\boldsymbol{C}_{\mathbf{2}}$} & \multicolumn{1}{c}{$\boldsymbol{C}_{\mathbf{3}}$} & \multicolumn{1}{c}{$\boldsymbol{C}_{\mathbf{4}}$} & $\boldsymbol{C}_{\mathbf{5}}$ & $\boldsymbol{C}_{\mathbf{6}}$ & $\boldsymbol{C}_{\mathbf{7}}$ & $\boldsymbol{C}_{\mathbf{8}}$ & $\boldsymbol{C}_{\mathbf{9}}$ & $\boldsymbol{C}_{\mathbf{1 0}}$ \\
\hline$\phi_{j}^{1}\left(S_{\mathbf{1}}, S_{2}\right)$ & 0.010 & 0.065 & -0.219 & -0.312 & -0.240 & 0.118 & 0.303 & 0.005 & 0.121 & -0.217 \\
$\phi_{j}^{1}\left(S_{\mathbf{1}}, S_{3}\right)$ & -0.040 & -0.046 & 0.001 & -0.205 & -0.203 & -0.205 & 0.281 & -0.253 & -0.093 & -0.401 \\
$\phi_{j}^{1}\left(S_{\mathbf{1}}, S_{4}\right)$ & 0.287 & 0.209 & 0.275 & -0.149 & 0.045 & -0.035 & 0.556 & -0.131 & 0.126 & -0.223 \\
$\phi_{j}^{1}\left(S_{2}, S_{3}\right)$ & -0.050 & -0.111 & 0.220 & 0.107 & 0.038 & -0.143 & -0.022 & -0.258 & -0.214 & -0.184 \\
$\phi_{j}^{1}\left(S_{2}, S_{4}\right)$ & 0.277 & 0.144 & 0.494 & 0.163 & 0.285 & -0.153 & 0.253 & -0.136 & 0.004 & -0.006 \\
$\phi_{j}^{1}\left(S_{3}, S_{4}\right)$ & 0.327 & 0.255 & 0.274 & 0.056 & 0.247 & -0.010 & 0.275 & 0.123 & 0.219 & 0.178 \\
\hline
\end{tabular}

CDI, concordance/discordance index.

bigger and bigger, and the negative CCDI values are getting smaller and smaller with the increasing of regret aversion coefficient $\delta$. The greatest CCDI value always corresponds to the permutation $P_{15}$, which demonstrates that the priority of all sustainable suppliers is $S_{3}>S_{2}>S_{1}>S_{4}$.

\subsection{Comparisons and Discussion}

To validate the effectiveness and advantage of the presented method (QUALIFLEX-RT), some existing approaches are used to conduct a comparative analysis, including the TODIM approach [5] and the 
Table 9 The results of WCDI for all permutations.

\begin{tabular}{|c|c|c|c|c|c|c|c|}
\hline$P_{1}$ & WCDI & $P_{2}$ & WCDI & $P_{3}$ & WCDI & $P_{4}$ & WCDI \\
\hline$\phi^{1}\left(S_{1}, S_{2}\right)$ & -0.039 & $\phi^{2}\left(S_{1}, S_{2}\right)$ & -0.039 & $\phi^{3}\left(S_{1}, S_{2}\right)$ & -0.039 & $\phi^{4}\left(S_{1}, S_{2}\right)$ & -0.039 \\
\hline$\phi^{1}\left(S_{1}, S_{3}\right)$ & -0.078 & $\phi^{2}\left(S_{1}, S_{3}\right)$ & -0.078 & $\phi^{3}\left(S_{1}, S_{3}\right)$ & -0.078 & $\phi^{4}\left(S_{1}, S_{3}\right)$ & -0.078 \\
\hline$\phi^{1}\left(S_{1}, S_{4}\right)$ & 0.129 & $\phi^{2}\left(S_{1}, S_{4}\right)$ & 0.129 & $\phi^{3}\left(S_{1}, S_{4}\right)$ & 0.129 & $\phi^{4}\left(S_{1}, S_{4}\right)$ & 0.129 \\
\hline$\phi^{1}\left(S_{2}, S_{3}\right)$ & -0.039 & $\phi^{2}\left(S_{2}, S_{3}\right)$ & -0.039 & $\phi^{3}\left(S_{2}, S_{4}\right)$ & 0.168 & $\phi^{4}\left(S_{3}, S_{2}\right)$ & 0.039 \\
\hline$\phi^{1}\left(S_{2}, S_{4}\right)$ & 0.168 & $\phi^{2}\left(S_{2}, S_{4}\right)$ & 0.168 & $\phi^{3}\left(S_{3}, S_{2}\right)$ & 0.039 & $\phi^{4}\left(S_{3}, S_{4}\right)$ & 0.207 \\
\hline$\phi^{1}\left(S_{3}, S_{4}\right)$ & 0.207 & $\phi^{2}\left(S_{4}, S_{3}\right)$ & 0.207 & $\phi^{3}\left(S_{3}, S_{4}\right)$ & 0.207 & $\phi^{4}\left(S_{4}, S_{2}\right)$ & -0.168 \\
\hline$P_{5}$ & WCDI & $P_{6}$ & WCDI & $P_{7}$ & WCDI & $P_{8}$ & WCDI \\
\hline$\phi^{5}\left(S_{1}, S_{2}\right)$ & -0.039 & $\phi^{6}\left(S_{1}, S_{2}\right)$ & -0.039 & $\phi^{7}\left(S_{1}, S_{3}\right)$ & -0.078 & $\phi^{8}\left(S_{1}, S_{3}\right)$ & -0.078 \\
\hline$\phi^{5}\left(S_{1}, S_{3}\right)$ & -0.078 & $\phi^{6}\left(S_{1}, S_{3}\right)$ & -0.078 & $\phi^{7}\left(S_{1}, S_{4}\right)$ & 0.129 & $\phi^{8}\left(S_{1}, S_{4}\right)$ & 0.129 \\
\hline$\phi^{5}\left(S_{1}, S_{4}\right)$ & 0.129 & $\phi^{6}\left(S_{1}, S_{4}\right)$ & 0.129 & $\phi^{7}\left(S_{2}, S_{1}\right)$ & 0.039 & $\phi^{8}\left(S_{2}, S_{1}\right)$ & 0.039 \\
\hline$\phi^{5}\left(S_{2}, S_{3}\right)$ & -0.039 & $\phi^{6}\left(S_{3}, S_{2}\right)$ & 0.039 & $\phi^{7}\left(S_{2}, S_{3}\right)$ & -0.039 & $\phi^{8}\left(S_{2}, S_{3}\right)$ & -0.039 \\
\hline$\phi^{5}\left(S_{4}, S_{2}\right)$ & -0.168 & $\phi^{6}\left(S_{4}, S_{2}\right)$ & -0.168 & $\phi^{7}\left(S_{2}, S_{4}\right)$ & 0.168 & $\phi^{8}\left(S_{2}, S_{4}\right)$ & 0.168 \\
\hline$\phi^{5}\left(S_{4}, S_{3}\right)$ & -0.207 & $\phi^{6}\left(S_{4}, S_{3}\right)$ & -0.207 & $\phi^{7}\left(S_{3}, S_{4}\right)$ & 0.207 & $\phi^{8}\left(S_{4}, S_{3}\right)$ & -0.207 \\
\hline$P_{9}$ & WCDI & $P_{10}$ & WCDI & $P_{11}$ & WCDI & $P_{12}$ & WCDI \\
\hline$\phi^{9}\left(S_{1}, S_{4}\right)$ & 0.129 & $\phi^{10}\left(S_{2}, S_{1}\right)$ & 0.039 & $\phi^{11}\left(S_{1}, S_{3}\right)$ & -0.078 & $\phi^{12}\left(S_{2}, S_{1}\right)$ & 0.039 \\
\hline$\phi^{9}\left(S_{2}, S_{1}\right)$ & 0.039 & $\phi^{10}\left(S_{2}, S_{3}\right)$ & -0.039 & $\phi^{11}\left(S_{2}, S_{1}\right)$ & 0.039 & $\phi^{12}\left(S_{2}, S_{3}\right)$ & -0.039 \\
\hline$\phi^{9}\left(S_{2}, S_{3}\right)$ & -0.039 & $\phi^{10}\left(S_{2}, S_{4}\right)$ & 0.168 & $\phi^{11}\left(S_{2}, S_{3}\right)$ & -0.039 & $\phi^{12}\left(S_{2}, S_{4}\right)$ & 0.168 \\
\hline$\phi^{9}\left(S_{2}, S_{4}\right)$ & 0.168 & $\phi^{10}\left(S_{3}, S_{1}\right)$ & 0.078 & $\phi^{11}\left(S_{2}, S_{4}\right)$ & 0.168 & $\phi^{12}\left(S_{3}, S_{1}\right)$ & 0.078 \\
\hline$\phi^{9}\left(S_{3}, S_{1}\right)$ & 0.078 & $\phi^{10}\left(S_{3}, S_{4}\right)$ & 0.207 & $\phi^{11}\left(S_{4}, S_{1}\right)$ & -0.129 & $\phi^{12}\left(S_{4}, S_{1}\right)$ & -0.129 \\
\hline$\phi^{9}\left(S_{3}, S_{4}\right)$ & 0.207 & $\phi^{10}\left(S_{4}, S_{1}\right)$ & -0.129 & $\phi^{11}\left(S_{4}, S_{3}\right)$ & -0.207 & $\phi^{12}\left(S_{4}, S_{3}\right)$ & -0.207 \\
\hline$P_{13}$ & WCDI & $P_{14}$ & WCDI & $P_{15}$ & WCDI & $P_{16}$ & WCDI \\
\hline$\phi^{13}\left(S_{1}, S_{2}\right)$ & -0.039 & $\phi^{14}\left(S_{1}, S_{2}\right)$ & -0.039 & $\phi^{15}\left(S_{1}, S_{4}\right)$ & 0.129 & $\phi^{16}\left(S_{2}, S_{1}\right)$ & 0.039 \\
\hline$\phi^{13}\left(S_{1}, S_{4}\right)$ & 0.129 & $\phi^{14}\left(S_{1}, S_{4}\right)$ & 0.129 & $\phi^{15}\left(S_{2}, S_{1}\right)$ & 0.039 & $\phi^{16}\left(S_{2}, S_{4}\right)$ & 0.168 \\
\hline$\phi^{13}\left(S_{2}, S_{4}\right)$ & 0.168 & $\phi^{14}\left(S_{3}, S_{1}\right)$ & 0.078 & $\phi^{15}\left(S_{2}, S_{4}\right)$ & 0.168 & $\phi^{16}\left(S_{3}, S_{1}\right)$ & 0.078 \\
\hline$\phi^{13}\left(S_{3}, S_{1}\right)$ & 0.078 & $\phi^{14}\left(S_{3}, S_{2}\right)$ & 0.039 & $\phi^{15}\left(S_{3}, S_{1}\right)$ & 0.078 & $\phi^{16}\left(S_{3}, S_{2}\right)$ & 0.039 \\
\hline$\phi^{13}\left(S_{3}, S_{2}\right)$ & 0.039 & $\phi^{14}\left(S_{3}, S_{4}\right)$ & 0.207 & $\phi^{15}\left(S_{3}, S_{2}\right)$ & 0.039 & $\phi^{16}\left(S_{3}, S_{4}\right)$ & 0.207 \\
\hline$\phi^{13}\left(S_{3}, S_{4}\right)$ & 0.207 & $\phi^{14}\left(S_{4}, S_{2}\right)$ & -0.168 & $\phi^{15}\left(S_{3}, S_{4}\right)$ & 0.207 & $\phi^{16}\left(S_{4}, S_{1}\right)$ & -0.129 \\
\hline$P_{17}$ & WCDI & $P_{18}$ & WCDI & $P_{19}$ & WCDI & $P_{20}$ & WCDI \\
\hline$\phi^{17}\left(S_{1}, S_{2}\right)$ & -0.039 & $\phi^{18}\left(S_{2}, S_{1}\right)$ & 0.039 & $\phi^{19}\left(S_{1}, S_{2}\right)$ & -0.039 & $\phi^{20}\left(S_{1}, S_{2}\right)$ & -0.039 \\
\hline$\phi^{17}\left(S_{3}, S_{1}\right)$ & 0.078 & $\phi^{18}\left(S_{3}, S_{1}\right)$ & 0.078 & $\phi^{19}\left(S_{1}, S_{3}\right)$ & -0.078 & $\phi^{20}\left(S_{1}, S_{3}\right)$ & -0.078 \\
\hline$\phi^{17}\left(S_{3}, S_{2}\right)$ & 0.039 & $\phi^{18}\left(S_{3}, S_{2}\right)$ & 0.039 & $\phi^{19}\left(S_{2}, S_{3}\right)$ & -0.039 & $\phi^{20}\left(S_{3}, S_{2}\right)$ & 0.039 \\
\hline$\phi^{17}\left(S_{3}, S_{4}\right)$ & 0.207 & $\phi^{18}\left(S_{3}, S_{4}\right)$ & 0.207 & $\phi^{19}\left(S_{4}, S_{1}\right)$ & -0.129 & $\phi^{20}\left(S_{4}, S_{1}\right)$ & -0.129 \\
\hline$\phi^{17}\left(S_{4}, S_{1}\right)$ & -0.129 & $\phi^{18}\left(S_{4}, S_{1}\right)$ & -0.129 & $\phi^{19}\left(S_{4}, S_{2}\right)$ & -0.167 & $\phi^{20}\left(S_{4}, S_{2}\right)$ & -0.168 \\
\hline$\phi^{17}\left(S_{4}, S_{2}\right)$ & -0.168 & $\phi^{18}\left(S_{4}, S_{2}\right)$ & -0.168 & $\phi^{19}\left(S_{4}, S_{3}\right)$ & -0.207 & $\phi^{20}\left(S_{4}, S_{3}\right)$ & -0.207 \\
\hline$P_{21}$ & WCDI & $P_{22}$ & WCDI & $P_{23}$ & WCDI & $P_{24}$ & WCDI \\
\hline$\phi^{21}\left(S_{1}, S_{3}\right)$ & -0.078 & $\phi^{22}\left(S_{2}, S_{1}\right)$ & 0.039 & $\phi^{23}\left(S_{1}, S_{2}\right)$ & -0.039 & $\phi^{24}\left(S_{2}, S_{1}\right)$ & 0.039 \\
\hline$\phi^{21}\left(S_{2}, S_{1}\right)$ & 0.039 & $\phi^{22}\left(S_{2}, S_{3}\right)$ & -0.039 & $\phi^{23}\left(S_{3}, S_{1}\right)$ & 0.078 & $\phi^{24}\left(S_{3}, S_{1}\right)$ & 0.078 \\
\hline$\phi^{21}\left(S_{2}, S_{3}\right)$ & -0.039 & $\phi^{22}\left(S_{3}, S_{1}\right)$ & 0.078 & $\phi^{23}\left(S_{3}, S_{2}\right)$ & 0.039 & $\phi^{24}\left(S_{3}, S_{2}\right)$ & 0.039 \\
\hline$\phi^{21}\left(S_{4}, S_{1}\right)$ & -0.129 & $\phi^{22}\left(S_{4}, S_{1}\right)$ & -0.129 & $\phi^{23}\left(S_{4}, S_{1}\right)$ & -0.129 & $\phi^{24}\left(S_{4}, S_{1}\right)$ & -0.129 \\
\hline$\phi^{21}\left(S_{4}, S_{2}\right)$ & -0.168 & $\phi^{22}\left(S_{4}, S_{2}\right)$ & -0.168 & $\phi^{23}\left(S_{4}, S_{2}\right)$ & -0.168 & $\phi^{24}\left(S_{4}, S_{2}\right)$ & -0.168 \\
\hline$\phi^{21}\left(S_{4}, S_{3}\right)$ & -0.207 & $\phi^{22}\left(S_{4}, S_{3}\right)$ & -0.207 & $\phi^{23}\left(S_{4}, S_{3}\right)$ & -0.207 & $\phi^{24}\left(S_{4}, S_{3}\right)$ & -0.207 \\
\hline
\end{tabular}

WCDI, weighted concordance/discordance index.

WASPAS method [47]. Besides, we also adopted the approach based on the 2-DULWA operator to derive the priority of sustainable suppliers. Utilizing the QUALIFLEX-RT approach and the three methods mentioned above, the ranking results of four sustainable suppliers are displayed in Figure 4.
As shown in Figure 4, we can observe that the ranking result of sustainable suppliers determined by the WASPAS method is the same as that derived by the 2-DULWA operator, that is, $S_{2}>S_{3}>S_{4}>$ $S_{1}$. But both results of which are completely different from that produced by the QUALIFLEX-RT approach. Moreover, the priority 
Table 10 The results of CCDI for all permutations.

\begin{tabular}{lrlrcccccrrr}
\hline $\boldsymbol{P}_{\boldsymbol{\tau}}$ & CCDI & $\boldsymbol{P}_{\boldsymbol{\tau}}$ & CCDI & $\boldsymbol{P}_{\boldsymbol{\tau}}$ & CCDI & $\boldsymbol{P}_{\boldsymbol{\tau}}$ & CCDI & $\boldsymbol{P}_{\boldsymbol{\tau}}$ & CCDI & $\boldsymbol{P}_{\boldsymbol{\tau}}$ & CCDI \\
\hline$P_{1}$ & 0.348 & $P_{5}$ & -0.400 & $P_{9}$ & 0.581 & $P_{13}$ & 0.581 & $P_{17}$ & -0.012 & $P_{21}$ & -0.581 \\
$P_{2}$ & -0.065 & $P_{6}$ & -0.323 & $P_{10}$ & 0.323 & $P_{14}$ & 0.246 & $P_{18}$ & 0.065 & $P_{22}$ & -0.465 \\
$P_{3}$ & 0.426 & $P_{7}$ & 0.426 & $P_{11}$ & -0.246 & $P_{15}$ & 0.659 & $P_{19}$ & -0.659 & $P_{23}$ & -0.426 \\
$P_{4}$ & 0.091 & $P_{8}$ & 0.012 & $P_{12}$ & -0.091 & $P_{16}$ & 0.400 & $P_{20}$ & -0.581 & $P_{24}$ & -0.348 \\
\hline
\end{tabular}

CCDI, comprehensive concordance/discordance index.

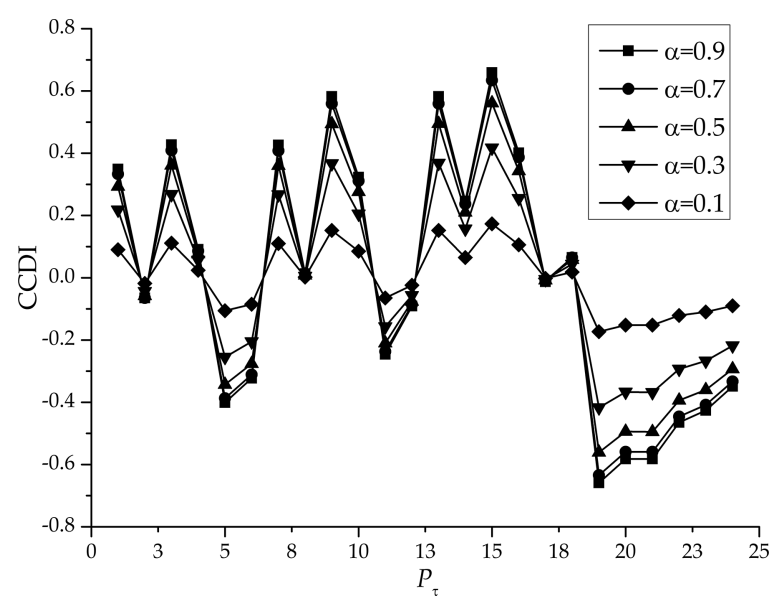

Figure 2 The CCDI values with different $\alpha$.

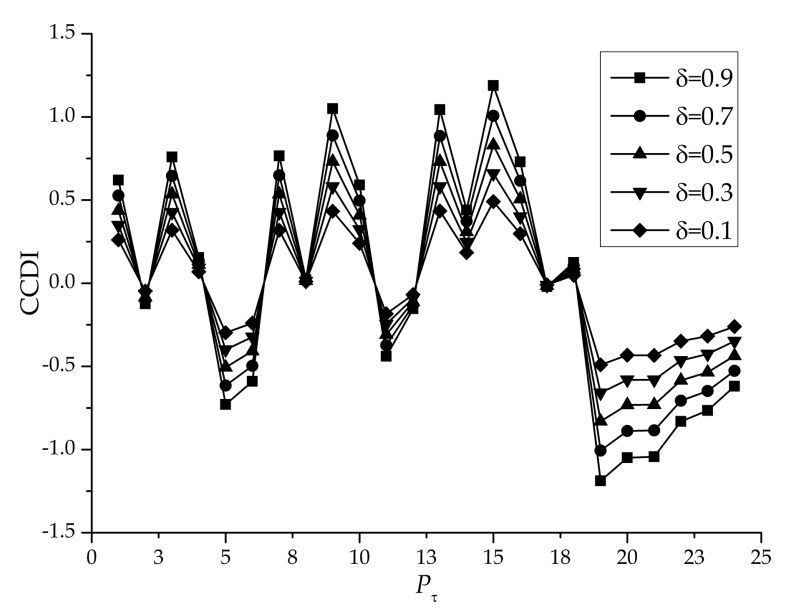

Figure 3 The CCDI values with different $\delta$.

of sustainable suppliers obtained by the QUALIFLEX-RT and the TODIM approaches are consistent, that is, $S_{3}>S_{2}>S_{1}>S_{4}$.

The main reason that results in the ranking difference is that the WASPAS method integrating the weighted sum model and the weighted product model and the approach based on the 2-DULWA operator assume that the decision-makers are completely rationality. This assumption is unreasonable in the decision-making process. Therefore, the result obtained by the QUALIFLEX-RT approach introducing the regret theory is more reasonable because it takes into account the regret aversion behavior of decisionmakers. Another reason may be that the presented approach uses the 2-DULV including the reliability of evaluation information to evaluate the sustainable suppliers. Whereas the WASPAS method adopts interval type-2 fuzzy sets to evaluate the performance of sustainable suppliers, which may lead to a biased result due to not incorporate the reliability of the evaluation information.

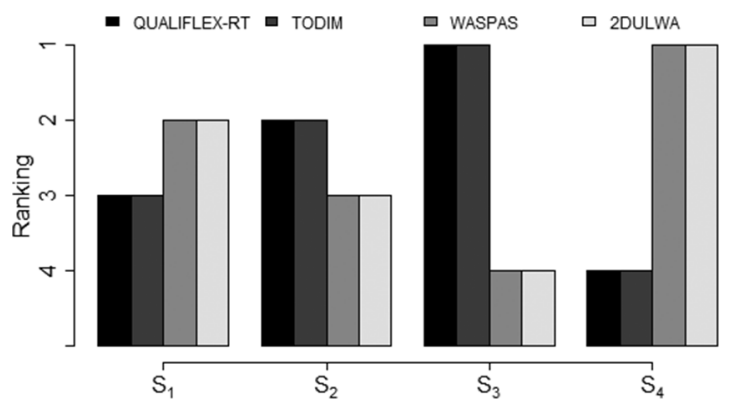

Figure 4 The ranking results of different methods.

The main reason behind the consistent ranking between the TODIM method and the QUALIFLEX-RT approach can be explained that the bounded rationality behavior of decision-makers is considered by the two methods. The same ranking results also validate the effectiveness and feasibility of the presented approach. Consequently, the ranking result of sustainable suppliers determined by the QUALIFLEX-RT is accurate and reasonable.

Compared with the 2-DULWA operator, the TODIM method and the WASPAS approach, the QUALIFLEX-RT method offers the following advantages: (1) The presented approach adopts the 2-DULV to assessment the performance of sustainable suppliers, which can better describe the ambiguity, uncertainty, and reliability of decision-makers judgment; (2) The QUALIFLEX-RT method based on the regret theory is utilized to determine the ranking of sustainable suppliers, which can better depict the decision-makers' bounded rationality behavior in the decision-making process.

Although the presented model has some advantages, there are also existing several drawbacks, which need to be further explored in the future. Firstly, the proposed method does not consider the interdependent relationship between the evaluation criteria, but these interactions generally exist in the sustainable supplier selection. In the future, we can introduce the Choquet integral [48] and power aggregation operator [49] into the proposed model to depict this interdependent relationship. Secondly, the consensus level between decision-makers is an important factor in decision-making which has been studied by some researchers [50,51], therefore we can include the consensus level in future sustainable supplier selection study. Furthermore, the presented method in this paper can be utilize to handle other MCDM problems, such as emergency management [52], site selection [53], and risk assessment [54], and so on, to further illustrate its effectiveness.

\subsection{Managerial Implications}

The main intent of this study helps managers of companies to select the best sustainable supplier for enhancing competitive advantage 
by developing a hybrid model combing 2-dimensional uncertain linguistic variable, regret theory, and QUALIFLEX method. Consequently, managerial implications are as follows:

i. The presented model by adopting 2-DULV to express the assessment information offers an effective and flexible approach for enterprise managers to cope with a multitude of vagueness and uncertainty information of decision-makers' evaluation in the sustainable supplier selection.

ii. The presented model adopted regret theory to depict the psychological behaviors of decision-makers under the uncertain environment. In previous studies, the behavior experiment results indicate that decision-makers' psychological behaviors have significant influences on the ranking results of alternatives. Consequently, enterprises' managers should consider the psychological behaviors of decision-makers in sustainable supplier selection.

iii. Through conducting the proposed method, the enterprise can enhance the performance and competitiveness of its supply chain by selecting the best sustainable supplier, and suppliers can discover their manage shortcomings and propose some corrective actions. To do so, between enterprises and their suppliers can establish a strategical partner relationship.

\section{CONCLUSION}

This paper investigates the sustainable supplier selection problem by presenting a novel model integrating the regret theory and the QUALIFLEX approach under a 2-DULVs environment. In this model, 2-DULVs are employed by decision-makers to evaluate the performance of sustainable suppliers on criteria. A similarity degree method is utilized to determine the weight of decision-makers. Then we established a maximizing deviation model to calculate the criteria weights, and an improved QUALIFLEX approach based on the regret theory is used for deriving the ranking result of sustainable suppliers. Ultimately, a numerical example of an automobile manufacturer is provided to demonstrate the effectiveness and feasibility of the presented model. Moreover, the results of a comparative analysis show that the presented method is the ability to describe the bounded rationality behavior of decision-makers and is an effective approach to determine the ranking order of sustainable suppliers.

\section{CONFLICT OF INTEREST}

The authors declare they have no conflicts of interest.

\section{AUTHORS' CONTRIBUTIONS}

Concept of this study, Limei Liu, Zhongli Bin, and Biao Shi; methodology, Limei Liu and Wenzhi Cao; writing-original draft preparation, Limei Liu; writing-review and editing, Zhongli Bin and Biao Shi.

\section{ACKNOWLEDGMENTS}

This research was funded by the National Social Science Fund of P.R. China (Grant No.18BGL181).

\section{REFERENCES}

[1] M.L. Tseng, M. Lim, K.J. Wu, L. Zhou, D.T.D. Bui, A novel approach for enhancing green supply chain management using converged interval-valued triangular fuzzy numbers-grey relation analysis, Resour. Conserv. Recy. 128 (2018), 122-133.

[2] Z. Xu, J. Qin, J. Liu, L. Martinez, Sustainable supplier selection based on AHPSort II in interval type-2 fuzzy environment, Inf. Sci. 483 (2019), 273-293.

[3] A. Cheraghalipour, S. Farsad, A bi-objective sustainable supplier selection and order allocation considering quantity discounts under disruption risks: a case study in plastic industry, Comput. Ind. Eng. 118 (2018), 237-250.

[4] A. Memari, A. Dargi, M.R.A. Jokar, R. Ahmad, A.R.A. Rahim, Sustainable supplier selection: a multi-criteria intuitionistic fuzzy TOPSIS method, J. Manuf. Syst. 50 (2019), 9-24.

[5] J. Qin, X. Liu, W. Pedrycz, An extended TODIM multi-criteria group decision making method for green supplier selection in interval type-2 fuzzy environment, Eur. J. Oper. Res. 258 (2017), 626-638.

[6] G.H. Goren, A decision framework for sustainable supplier selection and order allocation with lost sales, J. Clean. Prod. 183 (2018), 1156-1169.

[7] C. Yu, Y. Shao, K. Wang, L. Zhang, A group decision making sustainable supplier selection approach using extended TOPSIS under interval-valued Pythagorean fuzzy environment, Expert Syst. Appl. 121 (2019), 1-17.

[8] C. Blome, D. Hollos, A. Paulraj. Green procurement and green supplier development: antecedents and effects on supplier performance, Int. J. Prod. Res. 52 (2014), 32-49.

[9] S.M. Chen, W.H. Han, An improved MADM method using interval-valued intuitionistic fuzzy values, Inf. Sci. 467 (2018), 489-505.

[10] Z. Wu, J. Xu, X. Jiang, L. Zhong, Two MAGDM models based on hesitant fuzzy linguistic term sets with possibility distributions: VIKOR and TOPSIS, Inf. Sci. 473 (2019), 101-120.

[11] M. Rabbani, N. Foroozesh, S M. Mousavi, H. Farrokhi-Asl, Sustainable supplier selection by a new decision model based on interval-valued fuzzy sets and possibilistic statistical reference point systems under uncertainty, Int. J. Syst. Sci. Oper. Log. 6 (2019), 162-178.

[12] N. Foroozesh, R. Tavakkoli-Moghaddam, S. Meysam Mousavi, Sustainable-supplier selection for manufacturing services: a failure mode and effects analysis model based on interval-valued fuzzy group decision-making, Int. J. Adv. Manuf. Technol. 95 (2018), 3609-3629.

[13] K. Govindan, R. Khodaverdi, A. Vafadarnikjoo, Intuitionistic fuzzy based DEMATEL method for developing green practices and performances in a green supply chain, Expert. Syst. Appl. 40 (2015), 7207-7220.

[14] R. Krishankumar, K.S. Ravichandran, A.B. Saeid, A new extension to PROMETHEE under intuitionistic fuzzy environment for solving supplier selection problem with linguistic preferences, Appl. Soft Comput. 60 (2017), 564-576.

[15] M.Y. Quan, Z.L. Wang, H.C. Liu, H. Shi, A hybrid MCDM approach for large group green supplier selection with uncertain linguistic information, IEEE Access. 6 (2018), 50372-50383.

[16] P. Liu, An approach to group decision making based on 2dimension uncertain linguistic information, Tech. Econ. Dev. 18 (2012), 424-437. 
[17] H.C. Liu, Y.P. Hu, J.J. Wang, M. Sun, Failure mode and effects analysis using two-dimensional uncertain linguistic variables and alternative queuing method, IEEE Trans. Reliab. 68 (2019), 554-565.

[18] Y. Wu, X. Sun, Z. Lu, J. Zhou, C. Xu, Optimal site selection of straw biomass power plant under 2-dimension uncertain linguistic environment, J. Clean. Prod. 212 (2019), 1179-1192.

[19] X.F. Ding, H.C. Liu, A 2-dimension uncertain linguistic DEMATEL method for identifying critical success factors in emergency management, Appl. Soft Comput. 71 (2018), 386-395.

[20] J. Li, H. Fang, W. Song, Sustainable supplier selection based on SSCM practices: a rough cloud TOPSIS approach, J. Clean. Prod. 222 (2019), 606-621.

[21] K. Govindan, M. Kadzinski, R. Sivakumar, Application of a novel PROMETHEE-based method for construction of a group compromise ranking to prioritization of green suppliers in food supply chain, Omega. 71 (2017), 129-145.

[22] A.R. Mishra, P. Ranbi, K.R. Pardasani, A. Mardani, A novel hesitant fuzzy WASPAS method for assessment of green supplier problem based on exponential information measures, J. Clean. Prod. 238 (2019), 117901.

[23] K.Q. Wang, H.C. Liu, L. Liu, J. Huang, Green supplier evaluation and selection using cloud model theory and the QUALIFLEX method, Sustainability. 9 (2017), 688.

[24] R. Liang, H.Y. Chong, A hybrid group decision model for green supplier selection: a case study of megaprojects, Eng. Constr. Archit. Ma. 26 (2019), 1712-1734.

[25] H. Fang, J. Li, W. Song, Sustainable site selection for photovoltaic power plant: An integrated approach based on prospect theory, Energy Convers. Manage. 174 (2018), 755-768.

[26] P. Phochanikorn, C. Tan, An integrated multi-criteria decisionmaking model based on prospect theory for green supplier selection under uncertain environment: a case study of the Thailand palm oil products industry, Sustainability. 11 (2018), 1872.

[27] H. Liao, D. Wu, Y. Huang, P. Ren, Z. Xu, M. Verma, Green logistic provider selection with a hesitant fuzzy linguistic thermodynamic method integrating cumulative prospect theory and PROMETHEE, Sustainability, 10 (2018), 1291.

[28] G. Loomes, R. Sugden, Regret theory: an alternative theory of rational choice under uncertainty, Trans. Econ. J. 92 (1982), 805-824.

[29] D.E. Bell, Regret in decision making under uncertainty, Oper. Res. 30 (1982), 961-981.

[30] J. Zhu, B. Shuai, G. Li, K.S. Chin, R. Wang, Failure mode and effect analysis using regret theory and PROMETHEE under linguistic neutrosophic context, J. Loss. Prevent. Proc. 64 (2020), 104048.

[31] P. Ji, h.Y. Zhang, J.Q. Wang, A fuzzy decision support model with sentiment analysis for items comparison in e-commerce: the case study of http://PConline.com, IEEE Trans. Syst. Man Cybern. Syst. 49 (2019), 1993-2004.

[32] K.W. Shen, X.K. Wang, D. Qiao, J.Q. Wang, Extended ZMABAC method based on regret theory and directed distance for regional circular economy development program selection with Z-information, IEEE Trans. Fuzzy Syst. 28 (2020), 1851-1863.

[33] H. Lu, S. Jiang, W. Song, X. Ming, A rough multi-criteria decision making approach for sustainable supplier selection under vague environment, Sustainability. 10 (2018), 2622.

[34] Q. Wu, L. Zhou, Y. Chen, H. Chen, An integrated approach to green supplier selection based on the interval type-2 fuzzy best-worst and extended VIKOR methods, Inf. Sci. 502 (2019), 394-417.

[35] P. Liu, Y. Wang, The aggregation operators based on the 2-dimension uncertain linguistic information and their application to decision making, Int. J. Mach. Learn. Cyber. 7 (2016), 1057-1074.

[36] J.H.P. Paelinck, Qualitative multiple criteria analysis, environmental protection and multiregional development, Pap. Reg. Sci. Assoc. 36 (1976), 59-76.

[37] T.Y. Chen, C.H. Chang, J.R. Lu, The extended QUALIFLEX method for multiple criteria decision analysis based on interval type-2 fuzzy sets and applications to medical decision making, Eur. J. Oper. Res. 226 (2013), 615-625.

[38] J.Y. Dong, Y. Chen, S.P. Wan, A cosine similarity based QUALIFLEX approach with hesitant fuzzy linguistic term sets for financial performance evaluation, Appl. Soft Comput. 69 (2018), 316-329.

[39] Z.P. Tian, R.X. Nie, J.Q. Wang, H. Luo, L Li, A prospect theorybased QUALIFLEX for uncertain linguistic Z-number multicriteria decision-making with unknown weight information, J. Intell. Fuzzy Syst. 38 (2020), 1775-1787.

[40] L. Wang, H.Y. Zhong, J.Q. Wang, G.F. Wu, Picture fuzzy multicriteria group decision-making method to hotel building energy efficiency retrofit project selection, PAIRO-Oper. Res. 54 (2020), 211-229.

[41] J. Von Neumann, O. Morgenstern, Theory of Games and Economic Behavior, first ed., Princeton University Press, Princeton, NJ, USA, 1944.

[42] A. Tversky, D. Kahneman, Advances in prospect theory: cumulative representation of uncertainty, J. Risk Uncertain. 5 (1992), 297-323.

[43] C.G. Chorus, Regret theory based route choices and traffic equilibria, Transportmetrica. 8 (2012), 291-305.

[44] J. Quiggin, Regret theory with general choice sets, J. Risk Uncertain. 8 (1994), 153-165.

[45] P. Liu, X. Yu, 2-Dimension uncertain linguistic power generalized weighted aggregation operator and its application in multiple attribute group decision making, Knowl. Based Syst. 57 (2014), 69-80.

[46] H.A. Zhou, S.Y. Liu, Projection method of fuzzy multi-attribute decision-making based on the maximal deviation model, Sys. Eng. Electron. 29 (2007), 741-744.

[47] M.K. Ghorabaee, E.K. Zavadskas, M. Amiri, A. Esmaeili, Multicriteria evaluation of green suppliers using an extended WASPAS metod with interval type-2 fuzzy sets, J. Clean. Prod. 137 (2016), 213-229.

[48] D. Candeloro, R. Mesiar, A.R. Sambucini, A special class of fuzzy measures Choquet integral and applications, Fuzzy Set Syst. 355 (2019), 83-99.

[49] J. Zhu, Y. Li, Hesitant fuzzy linguistic aggregation operators based on the hamacher t-norm and t-conorm, Symmetry. 10 (2018), 189.

[50] R. Wang, B. Shuai, Z.S.K.S. Chin, J.H. Zhu, Revisiting the role of hesitant multiplicative preference relations in group decision making with novel consistency improving and consensus reaching process, Int. J. Comput. Int. Sys. 12 (2019), 1029-1046.

[51] R. Wang, Y. Li, A novel approach for green supplier selection under a q-Rung orthopair fuzzy environment, Symmetry. 10 (2018), 687. 
[52] M. Nassereddine, A. Azar, A. Rajabzadeh, A. Afsar, Decision making application in collaborative emergency response: a new PROMETHEE preference function, Int. J. Disast. Risk Re. 38 (2019), 101221.

[53] M. Deveci, F. Canitez, I. Gokasar, WASPAS and TOPSIS based interval type-2 fuzzy MCDM method for a selection of a car sharing station, Sustain. Cities Soc. 41 (2018), 777-791.
[54] J. Zhu, B. Shuai, R. Wang, K.S. Chin, Risk assessment for failure mode and effects analysis using the Bonferroni mean and TODIM method, Mathematics. 7 (2019), 536. 